\title{
Citation:
}

Moore-Berg, S.L., Ankori-Karlinsky, L., Hameiri, B., \& Bruneau, E.G. (2020).

Exaggerated meta-perceptions predict intergroup hostility between American political partisans. Proceedings of the National Academy of Sciences, 117(26)

14864-14872. https://doi.org/10.1073/pnas.2001263117

\section{Exaggerated Meta-Perceptions Predict Intergroup Hostility Between American Political Partisans}

Samantha L. Moore-Berg ${ }^{1,2^{*}}$, Lee-Or Ankori-Karlinsky ${ }^{2}$, Boaz Hameiri ${ }^{1,2,3}$, Emile Bruneau ${ }^{1,2^{*}}$

${ }^{1}$ Annenberg School for Communication, University of Pennsylvania, 19104, Philadelphia, USA ${ }^{2}$ Beyond Conflict, 02108, Boston, USA

${ }^{3}$ The Evens Program in Conflict Resolution and Mediation, Tel Aviv University, 6997801, Tel Aviv-Yafo, Israel

Corresponding authors:

*Samantha L. Moore-Berg

Email: Samantha.mooreberg@asc.upenn.edu

* Emile Bruneau

Email: emile.bruneau@asc.upenn.edu 


\begin{abstract}
People's actions toward a competitive outgroup can be motivated not only by their perceptions of the outgroup, but also by how they think the outgroup perceives the ingroup (i.e., metaperceptions). Here we examine the prevalence, accuracy, and consequences of meta-perceptions among American political partisans. Using a representative sample $(N=1056)$ and a longitudinal convenience sample $(N=2707)$, we find that Democrats and Republicans equally dislike and dehumanize each other, but think that the levels of prejudice and dehumanization held by the outgroup party are approximately twice as strong as actually reported by a representative sample of Democrats and Republicans. Overestimations of negative meta-perceptions were consistent across samples, over time and between demographic subgroups, but were modulated by political ideology: more strongly liberal Democrats and more strongly conservative Republicans were particularly prone to exaggerate meta-perceptions. Finally, we show that meta-prejudice and meta-dehumanization are independently associated with desire for social distance from members of the outgroup party and support for policies that harm the country and flout democratic norms to favor the ingroup political party. This research demonstrates that partisan meta-perceptions are subject to a strong negativity bias, with Democrats and Republicans agreeing that the shadow of partisanship is much larger than it actually is, which fosters mutual intergroup hostility.
\end{abstract}




\section{Significance Statement}

Although much current research highlights differences between political partisans, our research provides evidence that strong partisan biases in meta-perceptions are largely symmetrical for Democrats and Republicans. This suggests that biased meta-perceptions are a consequence of shared psychology rather than merely a consequence of divergent ideological convictions. Metaperceptions represent evaluations that are distinct from perceptions at a core psychological level: While negative perceptions like dehumanization can be thought of as offensive or reprehensible, meta-perceptions are inferences about what others think and can therefore be false. The theoretical distinctions between perceptions and meta-perceptions suggest that practical approaches to reducing negative meta-perceptions may be distinct from those that aim to reduce negative perceptions. 
Disagreement is an integral component of a healthy democracy, but some forms of polarization may be toxic to Democracy (Svolik, 2019). What might lead people to support a style of governance that goes beyond advocacy of partisan social issues to threaten the fabric of society? One possibility lies in the shadow of political polarization (Moore-Berg, Hameiri, \& Bruneau, 2020). Recent polling data shows that nearly $70 \%$ of Democrats and Republicans believe that Americans are greatly divided on their most important values (Monmouth University, 2019), and both Democrats' and Republicans' levels of affective prejudice toward the other side are at a 40-year high (Iyengar, Lelkes, Levendusky, Malhotra, \& Westwood, 2019; Iyengar, Sood \& Lelkes, 2012). But is the shadow of partisanship as large as Americans believe it to be? Previous research suggests that it might not be (e.g., Chambers, Baron, \& Inman, 2006; Chambers \& Melnyk, 2006; Levendusky \& Malhotra, 2016; Robinson, Keltner, Ward, \& Ross, 1995; Sherman, Nelson, \& Ross, 2003; Westfall, Van Boven, Chambers, \& Judd, 2015). For example, research in political psychology reveals that the perceived extremity of outgroup positions on social issues is reliably exaggerated: When people are asked to report how the average partisan outgroup member stands on a social issue, both Democrats and Republicans predict that the outgroup holds views that are more extreme, and therefore more divergent from their own, than they are in reality (e.g., Chambers, Baron, \& Inman, 2006; Robinson, Keltner, Ward, \& Ross, 1995; Sherman, Nelson, \& Ross, 2003; Westfall, Van Boven, Chambers, \& Judd, 2015). This false polarization bias has been demonstrated over time and across a range of social issues (Westfall, Van Boven, Chambers, \& Judd, 2015); however, it remains unclear if a similar negativity bias is at play for perceptions that go beyond ideology, such as the degree to which partisans assume that the other political party dislikes and dehumanizes their own party (i.e., meta-prejudice and meta-dehumanization). In the current research, we investigated the 
prevalence, accuracy, and consequences of meta-prejudice and meta-dehumanization between political partisans in the United States.

The potential for meta-perceptions to sow political discord is supported by past research showing that ethnic and religious groups think that outgroup perceptions of the ingroup are more negative than those actually held by the outgroup (Kteily \& Bruneau, 2017; Vorauer, Hunter, Main, \& Roy, 2000; Vorauer, Main, \& O’Connell, 1998), and that these exaggerated metaperceptions are associated with support for intergroup aggression (Kteily \& Bruneau, 2017; Kteily, Hodson, \& Bruneau, 2016; O’Brien, Leidner, \& Tropp, 2018). For example, Kteily and colleagues $(2016,2017)$ examined the consequences of perceiving that the ingroup is disliked (i.e., meta-prejudice) and dehumanized (i.e., meta-dehumanization) by a competitive outgroup. Across a range of contexts and toward a number of target groups, these studies found that metaprejudice and meta-dehumanization are strong, independent, and complementary predictors of support for aggression toward the other side.

Therefore, both meta-prejudice and meta-dehumanization are subject to a strong negativity bias: We think that other groups have more hostile attitudes and intentions than they do in reality (Kteily \& Bruneau, 2017; O’Brien, Leidner, \& Tropp, 2018). Particularly given the American political partisans accessibility to the assessments of their own group by the other in a partisan media environment (Levendusky \& Malhotra, 2016), we predicted that meta-perceptions would also be present and relevant between political partisans. If political meta-perceptions are subject to the same negativity bias present for ethnic and religious groups, then Americans may overestimate the levels of political animus. And since meta-perceptions tend to drive negative perceptions of the other group (Kteily, Hodson, \& Bruneau, 2016), these negative meta- 
perceptions could become self-fulfilling by increasing negative perceptions of each side toward the other.

In the current research, we explore the possibility that negative perceptions thought to be held by the other political party are (1) perceived to be stronger than they are in reality, and (2) associated with intergroup hostility. We suggest that although intergroup prejudice and dehumanization are significant and consequential, the degree of prejudice and dehumanization believed to be held by the outgroup may be exaggerated, which could then lead to greater intergroup hostility. To determine the strength and accuracy of negative meta-perceptions, in Study 1 we collected a representative sample of Democrats and Republicans, and compared actual perceptions held by each group to the meta-perceptions each group inferred that the other holds toward them. To determine the persistence and consequences of negative metaperceptions, in Study 2 we used a two-wave study to examine how consistent meta-perceptions are over time, and how strongly meta-perceptions are associated with outcomes assessed three months later.

\section{Study 1}

In a preregistered study (https://osf.io/hnq7j/), we examined perceptions and metaperceptions in a nationally representative sample of Democrats and Republicans. The primary goal was to determine the accuracy of meta-prejudice (i.e., the amount of affective prejudice thought to be held by the political outgroup toward the political ingroup) and metadehumanization (i.e., the extent to which the political outgroup is thought to dehumanize the political ingroup) (Kteily, Hodson, \& Bruneau, 2016). We also examined the relevance of these meta-perceptions to political outcomes. We focused on two intergroup outcomes in the current study: First, we assessed desire for social distance from members of the political outgroup, which 
has been demonstrated previously to impede partisan unity (Iyengar, Lelkes, Levendusky, Malhotra, \& Westwood, 2019). Second, we aimed to capture desire for governance strategies that go beyond partisanship to include support for illegal or immoral behaviors that may fray democracy. To do this, we developed a measure of 'outgroup spite': support for policies and behaviors that help the ingroup political party but at the expense of the country and in contravention of democratic norms (for example, infringing on the Second Amendment (i.e., ensuring free speech) by shutting down liberal/conservative news outlets, illegally gerrymandering voting districts).

\section{Results}

See Table 1 for variable means ( $M$ 's), standard deviations ( $S D^{\prime}$ 's), and intercorrelations. The primary goal of Study 1 was to determine the strength, prevalence, and accuracy of meta-perceptions. To do this, we first established ground truth levels of prejudice and dehumanization reported by the representative sample of Democrats and Republicans. Consistent with past research among ethnic and religious groups (Bruneau \& Kteily, 2017), Republicans felt colder toward Democrats $(M=34.55, S D=29.02)$ than toward Republicans $(M=76.74, S D=$ $22.83 ; t(463)=24.47, p<.001, d=1.62)$ and denied humanity to Democrats $(M=62.36, S D=$ 35.70) more than to Republicans $(M=84.64, S D=21.35 ; t(461)=14.06, p<.001, d=.76)$; at the same time, Democrats felt colder toward Republicans $(M=32.82, S D=27.69)$ than toward Democrats $(M=77.95, S D=21.68 ; t(577)=30.97, p<.001, d=1.81)$ and denied humanity to Republicans $(M=61.56, S D=34.19)$ more than to Democrats $(M=83.31, S D=21.89 ; t(580)=$ 15.26, $p<.001, d=.76$ ) (see Figure 1 for dehumanization and SI Appendix, Figure S1 for prejudice). Democrats and Republicans did not differ from each other on expressed levels of 
warmth and humanity toward ingroup versus outgroup: prejudice $(t(1040)=1.31, p=.191, d=$ $.08)$ or dehumanization $(t(1041)=-.25, p=.804, d=.02)$.

Next, we examined meta-perceptions across both groups. As predicted, Democrats thought that Republicans felt colder toward Democrats $(M=21.99, S D=22.89)$ than toward Republicans $(M=88.13, S D=22.17 ; t(581)=47.32, p<.001, d=2.94)$ and thought that Republicans denied humanity to Democrats $(M=35.60, S D=29.71)$ more than to Republicans $(M=91.07, S D=18.89 ; t(575)=39.11, p<.001, d=2.23)$. Responses were similar for Republicans, who thought that Democrats felt colder toward Republicans $(M=14.29, S D=$ 17.85) than toward Democrats $(M=84.85, S D=22.27 ; t(465)=52.33, p<.001, d=3.50)$ and thought that Democrats denied humanity to Republicans $(M=28.47, S D=29.64)$ more than to Democrats $(M=87.85, S D=21.95 ; t(459)=36.72, p<.001, d=2.28)$ (see Figure 1 for metadehumanization and SI Appendix, Figure S1 for meta-prejudice). Democrats and Republicans did not differ from each other on levels of meta-dehumanization $(t(1034)=-1.82, p=.070, d=$ .11), but Republicans thought they were disliked by Democrats slightly more than Democrats thought they were disliked by Republicans $(t(1045)=-2.24, p=.025, d=.14)$.

To gain insight into the types of people who may be more or less susceptible to negative meta-perceptions, we calculated mean levels of meta-prejudice and meta-dehumanization by demographic subgroups (see SI Appendix, Table S4), and we conducted follow-up analyses across the demographic variables we collected (race, gender, age, education, region, strength of party identification) and across liberal-conservative political ideology. Although we found that some subgroups harbored slightly higher or lower levels of meta-prejudice and metadehumanization, given the number of subgroups analyzed and the lack of replication across studies, these results could be spurious. By contrast, strength of liberal-conservative political 
ideology was significantly correlated with both meta-prejudice and meta-dehumanization among Democrats (meta-prejudice: $r=-.18, p<.001$; meta-dehumanization: $r=-.14, p=.001$ ) and Republicans (meta-prejudice: $r=.22, p<.001$; meta-dehumanization: $r=.30, p<.001$ ).

Next, to examine the accuracy of intergroup meta-perceptions, we compared metaprejudice and meta-dehumanization inferred by each group to the actual ground truth levels of prejudice and dehumanization expressed by the representative sample of the other group. Overall, Democrats overestimated the levels of prejudice and dehumanization that Republicans harbor toward Democrats: Democrat meta-prejudice versus Republican actual prejudice $\left(M_{d i f f}=\right.$ $23.95 ; t(1044)=10.91, p<.001, d=.68)$, with $79 \%$ of Democrats numerically overestimating how much prejudice Republicans actually expressed toward Democrats; Democrat metadehumanization versus Republican actual dehumanization $\left(M_{\text {diff }}=33.20 ; t(1036)=15.61, p<\right.$ $.001, d=.97)$, with $79 \%$ of Democrats numerically overestimating how much Republicans actually dehumanize Democrats. In fact, Democrats' estimates of dehumanization held by the “average Republican" were higher than levels of dehumanization expressed even by those who identified as "Strong Republicans" $\left(M_{\text {diff }}=19.95 ; t(704)=5.90, p<.001, d=.55\right)$, and Democrats' estimates of Republicans' prejudice were equivalent to levels of prejudice expressed by "Strong Republicans" $\left(M_{\text {diff }}=2.49 ; t(711)=.77, p=.441, d=.08\right)$.

Republicans similarly overestimated Democrats' levels of prejudice and dehumanization: Republican meta-prejudice versus how much prejudice Democrats actually expressed $\left(M_{\text {diff }}=\right.$ $25.43 ; t(1042)=12.56, p<.001, d=.79)$, with $81 \%$ of Republicans numerically overestimating the amount of prejudice actually reported by Democrats; Republican meta-dehumanization versus how much Democrats actually dehumanize Republicans $\left(M_{\text {diff }}=37.62 ; t(1039)=17.47, p\right.$ $<.001, d=1.09$ ), with $82 \%$ of Republicans numerically overestimating how much Democrats' 
actually dehumanize Republicans. Again, Republicans' estimates of prejudice and dehumanization expressed by the "average Democrat" were significantly higher than prejudice and dehumanization expressed even by the most strongly identified Democrats (prejudice: $M_{\text {diff }}=$ $14.42 ; t(656)=5.29, p<.001, d=.43$; dehumanization: $M_{\text {diff }}=30.24 ; t(653)=10.01, p<.001, d$ $=.85)$.

Our final set of analyses examined whether and how strongly meta-perceptions predicted the outcome measures. Previous research found that part of the association between feeling dehumanized and aggressive outcomes was indirect and mediated via dehumanization and prejudice (Kteily \& Bruneau, 2017; Kteily, Hodson, \& Bruneau, 2016). That is, across a range of cultural contexts and target groups, part of the reason why those who feel dehumanized by an outgroup endorse hostile actions toward that outgroup is because they more strongly dislike and dehumanize the outgroup, in turn. We examined the same process here among American partisans using Hayes' (2018) PROCESS macro (Model 4) with 5,000 bootstrap resamples. Consistent with previous research (Kteily \& Bruneau, 2017; Kteily, Hodson, \& Bruneau, 2016), we found significant indirect effects from meta-dehumanization to both outcome measures via dehumanization and prejudice (see Table 2). A full path model revealed that metadehumanization was significantly associated with both dehumanization and prejudice, while meta-prejudice was only significantly associated with prejudice (Figure 2).

We also pre-registered an assessment of the accuracy and consequences of ideological perceptions about border security, a key political issue in the 2016 presidential elections and 2018 mid-term elections (Bradner \& Merica, 2018). Although we found that ideological perceptions were inaccurate (see SI Appendix, Figure S2 and Table S3) and sometimes significantly associated with outcomes (see SI Appendix, Table S2), these results did not 
fundamentally extend previous research on false polarization bias, beyond replicating those previous results. The ideological meta-perceptions were also difficult to compare directly to intergroup meta-perceptions, since the constructs are distinct: Perceived ideological polarization is determined by perceived evaluations of the ingroup and the outgroup, whereas metaperceptions are determined only by perceived evaluation of the ingroup and the outgroup by the outgroup. We report all results for ideological polarization, including comparisons between intergroup meta-perceptions and ideological misperceptions, in the SI Appendix (see SI Appendix, Figure S2, and Tables S2-S4).

\section{Study 2}

In Study 1, we used a representative sample to determine the prevalence and accuracy of meta-prejudice and meta-dehumanization. In Study 2, we focused on the consequences of these meta-perceptions. We assessed perceptions, meta-perceptions, and outcome measures at two time points among a sample of Democrats and Republicans, which allowed us to examine the stability of meta-perceptions, and whether meta-perceptions at Wave 1 predict outcomes over time. Wave 1 data were collected in early November 2018 right before the United States midterm elections, and Wave 2 data were collected nearly three months later, in late January 2019.

\section{Results}

See Table 3 for variable means, standard deviations, and intercorrelations.

As in Study 1, Republicans expressed significant levels of prejudice and dehumanization:

At each wave Republicans felt colder toward Democrats $\left(M_{\text {Wavel }}=38.56, S D_{\text {Wavel }}=30.60\right.$;

$\left.M_{\text {Wave2 }}=37.50, S D_{\text {Wave } 2}=30.52\right)$ than toward Republicans $\left(M_{\text {Wavel }}=74.54, S D_{\text {Wavel }}=24.22\right.$;

$\left.M_{\text {Wave2 }}=75.71, S D_{\text {Wave } 2}=22.98 ; p \mathrm{~s}<.001, d \mathrm{~s} \geq 1.30\right)$ and denied humanity to Democrats

$\left(M_{\text {Wavel }}=71.90, S D_{\text {Wave }}=33.08 ; M_{\text {Wave } 2}=71.94, S D_{\text {Wave } 2}=32.82\right)$ more than to Republicans 
$\left(M_{\text {Wavel }}=89.63, S D_{\text {Wavel }}=18.38 ; M_{\text {Wave } 2}=90.36, S D_{\text {Wave } 2}=16.49 ; p \mathrm{~s}<.001, d \mathrm{~s} \geq .66\right) ;$ at the same time, in both waves Democrats felt colder toward Republicans $\left(M_{\text {Wavel }}=32.18, S D_{\text {Wavel }}=\right.$ $\left.29.17 ; M_{\text {Wave } 2}=33.34, S D_{\text {Wave } 2}=29.38\right)$ than toward Democrats $\left(M_{\text {Wave }}=74.19, S D_{\text {Wave }}=\right.$ 22.87; $\left.M_{\text {Wave } 2}=74.07, S D_{\text {Wave } 2}=22.57 ; p \mathrm{~s}<.001, d \mathrm{~s} \geq 1.55\right)$ and denied humanity to Republicans $\left(M_{\text {Wave }}=70.95, S D_{\text {Wavel }}=33.43 ; M_{\text {Wave }}=71.92, S D_{\text {Wave } 2}=33.42\right)$ more than to Democrats $\left(M_{\text {Wavel }}=89.31, S D_{\text {Wavel }}=18.27 ; M_{\text {Wave } 2}=90.11, S D_{\text {Wave } 2}=16.99 ; p \mathrm{~s}<.001, d \mathrm{~s} \geq\right.$ .68) (see Figure 3 for dehumanization and SI Appendix, Figure S3 for prejudice). Overall, levels of prejudice and dehumanization were similar for Democrats and Republicans $(p s>.111, d \mathrm{~s} \leq$ $.07)$, with the exception of prejudice scores in Wave 1, which were slightly higher among Democrats than Republicans $(p<.001, d=.17)$.

Next, we examined meta-perceptions. Again consistent with Study 1, Democrats thought that Republicans felt colder toward Democrats $\left(M_{\text {Wavel }}=23.34, S D_{\text {Wave }}=23.38 ; M_{\text {Wave2 }}=25.11\right.$, $\left.S D_{\text {Wave } 2}=23.12\right)$ than toward Republicans $\left(M_{\text {Wave } 1}=92.35, S D_{\text {Wavel }}=16.56 ; M_{\text {Wave } 2}=91.93\right.$, $\left.S D_{\text {Wave } 2}=16.47 ; p \mathrm{~s}<.001, d \mathrm{~s} \geq 3.33\right)$ and denied humanity to Democrats $\left(M_{\text {Wavel }}=48.02\right.$, $\left.S D_{\text {Wavel }}=33.74 ; M_{\text {Wave2 }}=51.03, S D_{\text {Wave } 2}=32.95\right)$ more than to Republicans $\left(M_{\text {Wavel }}=95.28\right.$, $\left.S D_{\text {Wave } 1}=13.90 ; M_{\text {Wave } 2}=95.92, S D_{\text {Wave } 2}=12.54 ; p \mathrm{~s}<.001, d \mathrm{~s} \geq 1.80\right)$. Similarly, Republicans thought that Democrats felt colder toward Republicans $\left(M_{\text {Wavel }}=23.43, S D_{\text {Wave }}=24.80 ; M_{\text {Wave }}\right.$ $\left.=24.01, S D_{\text {Wave } 2}=25.08\right)$ than toward Democrats $\left(M_{\text {Wavel }}=91.01, S D_{\text {Wavel }}=17.23 ; M_{\text {Wave } 2}=\right.$ 92.33, $\left.S D_{\text {Wave2 }}=15.95 ; p \mathrm{~s}<.001, d \mathrm{~s} \geq 3.16\right)$ and thought that Democrats denied humanity to Republicans $\left(M_{\text {Wave }}=45.16, S D_{\text {Wavel }}=35.00 ; M_{\text {Wave } 2}=44.44, S D_{\text {Wave } 2}=34.30\right)$ more than to Democrats $\left(M_{\text {Wavel }}=94.09, S D_{\text {Wavel }}=15.07 ; M_{\text {Wave } 2}=95.05, S D_{\text {Wave } 2}=13.14 ; p \mathrm{~s}<.001, d \mathrm{~s} \geq\right.$ 1.82) (see Figure 3 for meta-dehumanization and SI Appendix, Figure S3 for meta-prejudice). Democrats and Republicans did not differ from each other on levels of meta-prejudice ( $p \mathrm{~s}>$ 
$.250, d \mathrm{~s} \geq .04)$ or meta-dehumanization $(p=.237, d=.05)$, except in Wave 2 where Republicans reported slightly higher levels of meta-dehumanization than Democrats $(p<.001, d=.16)$.

As in Study 1, we analyzed meta-perceptions across demographic subgroups (see SI Appendix, Table S4 for details). As in Study 1, meta-perceptions were largely consistent across demographic subgroups, but were significantly correlated with levels of liberal-conservative political ideology for Democrats (meta-prejudice: Wave 1: $r=-.28, p<.001$, Wave 2: $r=-.23, p$ $<.001$; meta-dehumanization: Wave 1: $r=-.18, p<.001$, Wave $2: r=-.15, p<.001)$ and Republicans (meta-prejudice: Wave 1: $r=.17, p<.001$, Wave 2: $r=.11, p=.003$; metadehumanization: Wave 1: $r=.13, p<.001$, Wave 2: $r=.14, p<.001)$.

Intergroup meta-perceptions were exaggerated, as in Study 1, by similarly high proportions of Democrats and Republicans (see SI Appendix, Table S3). Democrats overestimated mean levels of prejudice and dehumanization that Republicans harbor toward Democrats: Democrat meta-prejudice versus Republican actual prejudice $\left(M_{\text {diffwavel }}=33.03\right.$, $M_{\text {diffWave } 2}=28.60 ; p \mathrm{~s}<.001, d \mathrm{~s} \geq .88$ ), with at least $84 \%$ of Democrats at each wave numerically overestimating the amount of prejudice Republicans felt toward Democrats; Democrat metadehumanization versus Republican actual dehumanization $\left(M_{\text {diff Wavel }}=29.52, M_{\text {diff Wave2 }}=26.47\right.$; $p \mathrm{~s}<.001, d \mathrm{~s} \geq .88$ ), with at least $71 \%$ of Democrats at each wave numerically overestimating the amount that Republicans deny humanity to Democrats. As in Study 1, Democrats' estimates of prejudice and dehumanization by the "average Republican" were significantly higher than levels of prejudice and dehumanization expressed even by those who identified as "strong Republicans" at both Waves (prejudice: $M_{\text {diffWavel }}=13.91 ; M_{\text {diffWave } 2}=8.52 ; p s<.001, d s \geq .27$; dehumanization: $M_{\text {diffWave } 1}=17.14 ; M_{\text {diffWave } 2}=15.72 ; p s<.001, d s \geq .46$ ). 
Republicans similarly overestimated Democrats' levels of prejudice and dehumanization. Republican meta-prejudice versus Democrat actual prejudice $\left(M_{\text {diffWavel }}=25.57, M_{\text {diffWave } 2}=\right.$ $27.59 ; p s<.001, d s \geq .76$ ), with at least $79 \%$ of Republicans at each wave numerically overestimating prejudice; Republican meta-dehumanization versus Democrat actual dehumanization $\left(M_{\text {diffWave } 1}=30.57, M_{\text {diffWave } 2}=32.42 ; p \mathrm{~s}<.001, d \mathrm{~s} \geq .90\right)$, with at least $71 \%$ of Republicans at each wave numerically overestimating amount of dehumanization held by Democrats. In both waves, Republicans' estimates of prejudice and dehumanization expressed by the "average Democrat" were significantly higher than prejudice and dehumanization expressed even by the most strongly identified Democrats (prejudice: $M_{\text {diffWave }}=7.09 ; M_{\text {diffWave } 2}$ $=10.18 ; p \mathrm{~s}<.001, d s \geq .21 ;$ dehumanization: $M_{\text {diffWavel }}=21.54 ; M_{\text {diffWave } 2}=23.74 ; p \mathrm{~s}<.001, d s \geq$ $.59)$.

For Democrats and Republicans, meta-prejudice and meta-dehumanization were also greater than the ground truth levels of prejudice and dehumanization reported by the representative sample of Democrats and Republicans in Study 1 ( $p$ s $<.001, d s \geq .66$ ).

Finally, we determined how well intergroup meta-perceptions predicted outcomes. To take advantage of the two waves of Study 2, we examined whether meta-dehumanization measured at Wave 1 and the hostile outcome measures of outgroup social distancing and outgroup spite, both measured at Wave 2, were mediated by dehumanization and prejudice, both measured at Wave 1 (controlling for meta-prejudice measured at Wave 1). Analyses were conducted using Hayes' (2018) PROCESS macro (Model 4) with 5,000 bootstrap resamples. Consistent with Study 1, as well as previous research (Kteily \& Bruneau, 2017; Kteily, Hodson, \& Bruneau, 2016), we again found significant indirect effects from meta-dehumanization to the outcome measures via dehumanization and prejudice across our two outcome measures of social 
distancing and outgroup spite (see Table 4). As in Study 1, meta-dehumanization was again significantly associated with both dehumanization and prejudice, while meta-prejudice was only significantly associated with prejudice (Figure 4). All significant results remained significant when controlling for Wave 1 outcome measures.

As in Study 1, we also assessed ideological polarization, here across 3 ideological issues (borders, gun control, police culpability for shooting a black civilian), which we report in the SI Appendix (see SI Appendix, Tables S3-S5 and Figures S4-S6).

\section{General Discussion}

Across two studies involving both representative and longitudinal samples, we found that Democrats and Republicans demonstrate a consistent and persistent bias in how much prejudice and dehumanization they express toward their political outgroup. Yet despite these significant levels of prejudice and dehumanization, the amount of prejudice and dehumanization that each group thinks the other group harbors toward their own group is far greater: Across both studies, and over both waves of Study 2, Democrats and Republicans assumed that the levels of prejudice and dehumanization held by the other side (i.e., meta-prejudice and meta-dehumanization) were $50-300 \%$ higher than what was actually expressed by a representative sample of outgroup political partisans. This research therefore reveals a very strong and persistent negativity bias in partisan meta-perceptions, which is consistent with the negativity bias in meta-perceptions observed between ethnic and religious groups (Frey \& Tropp, 2006).

One surprising aspect of the current results was the strength of the meta-perceptions negativity bias. The fact that estimates of meta-prejudice and meta-dehumanization were even greater than the levels of prejudice and dehumanization reported by the most strongly identified partisans argues against the interpretation that people are merely attributing the views of the most 
partisan outgroup members to the outgroup as a whole. However, it is possible that metaperceptions are driven not by the most identified outgroup members, but by the most outspoken, abrasive, or sensationalist members of the other group. Alternatively, or in addition, negative meta-perceptions could be driven by perceptions about outgroup composition (Ahler \& Sood, 2018), political and cultural elites (Banda \& Cluverius, 2018), and/or through partisan media (Bail, 2018).

In addition to demonstrating the extent of partisan meta-perceptions, this research shows that meta-perceptions, particularly meta-dehumanization, are associated with politically relevant outcomes, mostly through their effects on prejudice and dehumanization. The indirect effects of meta-prejudice/meta-dehumanization on aggressive outcomes through prejudice/dehumanization parallels work with ethnic and religious groups (Kteily \& Bruneau, 2017; Kteily, Hodson, \& Bruneau, 2016). The fact that intergroup meta-perceptions are associated with outcomes over time lends support to the idea that meta-perceptions may play a causal role in driving political polarization and discord by convincing both sides that the ideological divide is wider than it is in reality.

In the current research we used a gestalt measure of dehumanization. This measure allowed us to efficiently assess and directly compare dehumanization by one group with metadehumanization inferred by the other group. However, this measure fails to distinguish between the different ways in which target groups might be dehumanized—for instance, animalistic versus mechanistic dehumanization (Haslam, 2006), or blatant dehumanization characterized by denying mind (Gray, Gray, \& Wegner, 2007) versus blatant dehumanization that endows savagery (Smith, 2011). Therefore, although we show here that Democrats and Republicans 
dehumanize each other to similar degrees, we were not able to determine if they dehumanize each other in similar ways.

The fact that perceptions of political outgroups, and behavioral intentions toward them, are associated with meta-perceptions suggests that interventions that safeguard against or correct meta-perceptions may provide an indirect way of reducing partisan animus. Since metaperceptions are exaggerated, this process would require people to update their meta-perceptions to match reality, which may be an easier 'sell' than asking participants to identify with or like the outgroup more than they do currently. Previous research in the intergroup literature provides evidence that this approach can work (Kteily, Hodson, \& Bruneau, 2016). For example, correcting negative meta-perceptions that are believed to be harbored by Muslims against Americans effectively reduces dehumanization of Muslims (Kteily, Hodson, \& Bruneau, 2016). In fact, recent research provides evidence that correcting ideological polarization between political partisans effectively reduces negative intergroup outcomes (Lees \& Cikara, 2020). Since the current research suggests that intergroup meta-perceptions may be more potent predictors of negative intergroup outcomes than ideological meta-perceptions, interventions that correct intergroup meta-perceptions may be even stronger than those that target ideological metaperceptions. Given the strong role of dehumanization in fostering intergroup aggression (Kteily, Hodson, \& Bruneau, 2016), exploring approaches that correct meta-dehumanization, in particular, may help mitigate toxic polarization that threatens bipartisanship and democratic norms.

\section{Conclusion}

Across a representative sample and a longitudinal sample, we find that Americans are clearly polarized by their dislike, dehumanization, and disagreement with the other party. 
However, the degree to which both parties think the other side dislikes and dehumanizes their own group is dramatically overestimated, which is associated with support not only for social distance from outgroup members, but also support for spiteful partisan behaviors that promote the ingroup party at the expense of the country. Thus, a preference for spiteful and exclusionary governance is rooted in the shared illusion that American political partisans dislike, dehumanize, and disagree with each other more than they do in reality.

\section{Study 1}

\section{Materials and Methods}

Participants. A power analysis indicated that 105 participants per group would be required to detect a medium effect $(d=.5)$ at an alpha of .95 . Samples of 651 participants per group would be required to detect a small effect size $(d=.2)$. To detect small-medium effects, we collected at least 500 Democrat participants and 500 Republican participants. We recruited 1265 participants to complete the study through the non-partisan research organization NORC at the University of Chicago; 212 participants failed an attention check question embedded in the survey ("Please select 5 for this question"), resulting in a final sample of 1056 participants (584 Democrats, 472 Republicans), which was representative in terms of age (Mage $=47.54$ years, $S D_{\text {age }}=16.71$ years $)$, gender $(54 \%$ female, $46 \%$ male $)$, race $(66 \%$ White, $15 \%$ Black, $15 \%$ Latinx, 2\% Asian, 2\% Other), and region (regional breakdown: 18\% Northeast, 22\% Midwest, $38 \%$ South, 22\% West). (For additional details on sampling and demographic benchmarks used for weighting, see SI Appendix, Table S1). We use weighted values in all Study 1 analyses. Participants were compensated $\$ 2.00$ for their time.

\section{Measures and Procedure}


Prior to the start of the both studies, all participants were informed that this study was being conducted by researchers at the University of Pennsylvania. They were told that the purpose of the study is to identify attitudes about social issues, that their participation in the study is completely voluntary, and that no identifying information (other than demographics) would be collected. All participants provided informed consent. Study procedures and protocols were approved by the University of Pennsylvania IRB prior to the start of the studies.

Demographics. Participants first reported their race, age, gender, regional location, education, political ideology (liberal-conservative), and political affiliation (as strong Democrat, strong Republican, moderate Democrat, moderate Republican, lean Democrat, lean Republican, or do not lean/independent/none). We consider 'Democrats' all those who indicated strong, moderate, or lean Democrat, and 'Republicans' all those who indicated strong, moderate, or lean Republican.

Prejudice. We assessed prejudice with feeling thermometers (Haddock, Zanna, \& Esses, 1993). Participants rated how warm they felt toward each target group, using a sliding scale anchored at very cold/unfavorable (0) and very warm/favorable (100). Target groups included Democrats, Republicans, and filler groups (Americans, undocumented migrants, Europeans). Presentation order of target groups was randomized within and across participants. As in Kteily et al. (2015), we created a difference score (ingroup - outgroup), with higher scores indicating greater affective prejudice toward the outgroup.

Dehumanization. We assessed dehumanization with the 'Ascent of (Hu)Man' scale (Kteily, Bruneau, Waytz, \& Cotterill, 2015). Participants rated how 'evolved and civilized' they considered each target group to be using a sliding scale spanning the 'Ascent of (Hu)Man' image, ranging from the leftmost unevolved/uncivilized image (0) to the rightmost 
evolved/civilized image (100). Target groups were the same as used for the prejudice measure, and presentation order was again randomized. As with the prejudice measure, we assessed dehumanization as a difference score (ingroup - outgroup).

Meta-Prejudice and Meta-Dehumanization. We modeled these measures after the prejudice and dehumanization measures. For each question, participants indicated how their political outgroup would rate Democrats and Republicans (and the other filler groups) on the feeling thermometer and 'Ascent of (Hu)Man' scales. As with prejudice and dehumanization, we defined meta-prejudice and meta-dehumanization as difference scores (how the outgroup was perceived to rate the outgroup versus ingroup).

Across individuals, presentation order of prejudice and dehumanization were randomized, order of meta-prejudice and meta-dehumanization were randomized, and presentation order of the perception and meta-perception questions were randomized.

Social Distancing. To assess the degree to which partisans desire to remain separate from outgroup members we used a measure based on the Bogardus (1947) Social Distance Scale: Participants indicated how comfortable they would feel if their doctor, child's teacher, or child's best friend was a member of their political outgroup using a sliding scale ranging from not at all (0) to very (100). We reverse scored results and averaged responses together to obtain a measure of desired social distance from the outgroup. $(\alpha$ : Democrats $=.95$, Republicans $=.91)$.

Outgroup Spite. We assessed outgroup spite by determining participants' willingness to harm the country or subvert Democratic norms in order to harm the outgroup political party with the following items: "I think [Democrats/Republicans] should do everything they can to hurt the [Republican/Democrat] Party, even if it is at the short-term expense of the country," "I think [Democrats/Republicans] should do everything in their power within the law to make it as 
difficult as possible for [Trump to run the government effectively/ Democrats to take part in governing the country]," "[Democrats/Republicans] should redraw districts to maximize their potential to win more seats in federal elections, even if it may be technically illegal," "If [Democrats/Republicans] gain control of all branches of government in 2020, they should use the Federal Communications Commission to heavily restrict or shut down [Fox News/MSNBC] to stop the spread of fake news," and "It's OK to sacrifice US economic prosperity in the shortterm in order to hurt [Republicans'/Democrats'] chances in future elections." We randomized presentation order for each participant and across participants. Participants responded using a Likert-scale anchored at strongly disagree (1) and strongly agree $(7) .(\alpha \mathrm{s}$ : Democrats $=.83$, Republicans $=.81)$.

We also included in Study 1 questions to assess perceived ideological polarization, which we evaluate in the SI Appendix, and a few exploratory items that were beyond the scope of the current research, and therefore excluded from the following analyses.

All materials and data can be found at: https://osf.io/hnq7j/

\section{Study 2}

\section{Materials and Methods}

Participants. We used the same power analysis criteria as in Study 1 and increased our sample size to account for potential attrition between Waves 1 and 2. We recruited 2780 participants at Wave 1 from Amazon's Mechanical Turk. Seventy-three participants failed the attention check question ("Please select 5 for this question"), leaving a final sample of 2707 participants (1579 Democrats and 1128 Republicans). Of the 2707 Wave 1 participants, 2051 
completed Wave 2 (74\% retention). ${ }^{*}$ One hundred and forty-two Wave 2 participants failed the Wave 2 attention check question ("Please select 5 for this question"), leaving 1909 participants (1115 Democrats, 794 Republicans) in the final Wave 2 sample (77\% White, 8\% Black, 6\% Latinx, 6\% Asian, 3\% Other; 53\% female, 47\% male; $M_{\text {age }}=39.89$ years, $S D_{\text {age }}=12.23$ years; regional breakdown: 17\% Northeast, 21\% Midwest, 39\% South, 23\% West). Although this sample was not nationally representative, it was similar to the benchmark data used for Study 1. (See SI Appendix, Table S1 for Study demographic details compared to benchmarks). Participants were compensated $\$ 1.50$ per wave for their time.

\section{Measures and Procedure}

Demographics (Wave 1 only). Participants answered the same demographic questions as in Study 1, and political affiliation was computed as in Study 1.

Perceptions and Meta-Perceptions. We measured and computed prejudice, dehumanization, meta-prejudice, and meta-dehumanization as in Study 1.

Social Distancing. We assessed social distancing as in Study 1. (as: Democrats: W1/W2 $=.94 / .95$, Republicans: W1/W2 = .93/.93).

Outgroup Spite. We assessed outgroup spite as in Study 1, but with a slightly modified set of six questions, which included two reverse-coded (R) items about support for bipartisanship: "I think the [Democrats/Republicans] should do everything they can to hurt the [Republican/Democrat] party, even if it is at the short-term expense of the country," "I think the [Democrats/Republicans] should [attempt to block Trump's nominees for government by any means necessary/push through Trump's nominees without any regard for Democrats'

\footnotetext{
*Attrition $\left(\mathrm{R}^{2}=.03\right)$ was not predicted by political affiliation $(p=.878)$, ethnicity $(p=.879)$, or gender $(p=.052)$, but was predicted by age $(p<.001)$ : younger participants were more likely to drop out of the Study between Wave 1 and Wave 2.
} 
objections]," "I think the [Democrats/Republicans] should do everything in their power within the law to make it as difficult as possible for [Trump to run the government effectively/Democrats to take part in governing the country]," "The [Republican/Democrat] party has proven that it does not deserve the good faith support of the [Democrats/Republicans] in any way," "I support the [Democrats/Republicans] working with their [Republican/Democrat] counterparts in a bipartisan way (R)," and "I think the [Democrats/Republicans] should reason with and negotiate with the [Republicans/Democrats] to get things done (R)." ( $\alpha$ s: Democrats: $\mathrm{W} 1 / \mathrm{W} 2=.81 / .83$, Republicans: $\mathrm{W} 1 / \mathrm{W} 2=.83 / .87)$.

As in Study 1, we also included in Study 2 questions to assess perceived ideological polarization (here, across 3 issues) (see SI Appendix, Tables S3-S5), and exploratory items that were beyond the scope of the current research, and therefore excluded from the following analyses. 


\section{Acknowledgments}

We would like to thank Jake Parelman, Roman Gallardo, and Julia Schetelig for their help with data collection and coding. 


\section{References}

D.J. Ahler, G. Sood, The parties in our heads: Misperceptions about party composition and their consequences. J. Politics, 80, 3, 964-981 (2018).

C.A. Bail et al., Exposure to opposing views on social media can increase political polarization. Proc. Natl. Acad. Sci. USA, 115, 37, 9216-9221 (2018).

K.K. Banda, J. Cluverius, J. Elite polarization, party extremity, and affective polarization. Elect. Stud., 56, 90-101 (2018).

E.S. Bogardus, Measurement of personal-group relations. Sociometry, 10, 4, 306-311 (1947).

E. Bradner, D. Merica, Trump's family separation policy has Republicans starting to panic about 2018. CNN Politics. Available at https://www.cnn.com/2018/06/18/politics/familyseparations-2018-midterms-republicans-trump/index.html (2018, June 18).

E. Bruneau, N. Kteily, The enemy as animal: Symmetric dehumanization during asymmetric warefare. PloS One. 12, 7 (2017).

J. Chambers, R. Baron, M. Inman, Misperceptions in intergroup conflict: Disagreeing about what we disagree about. Psychol. Sci., 17, 1, 38-45 (2006).

J. Chambers, D. Melnyk, Why do I hate thee? Conflict misperceptions and intergroup mistrust. Pers. Soc. Psychol. Bull., 32, 10, 1295-1311 (2006).

F. Frey, L. Tropp, Being seen as individuals versus as group members: extending research on metaperception to intergroup contexts. Pers. Soc. Psycho. Rev., 10, 3, 265-280 (2006).

H.M. Gray, K. Gray, D.M. Wegner, Dimensions of mind perception. Science, 315, 5812, 619619 (2007).

G. Haddock, M.P. Zanna, V.M. Esses, Assessing the structure of prejudicial attitudes: The case of attitudes toward homosexuals. J. Pers. Soc. Psychol, 65, (6), 1105-1118 (1993). 
N. Haslam, Dehumanization: An integrative review. Pers. Soc. Psychol. Rev., 10, 3, 252-264 (2006).

A.F. Hayes, An introduction to mediation, moderation, and conditional process analysis: A regression-based approach (2nd ed.), (Guilford Press, 2018).

S. Iyengar, Y. Lelkes, M. Levendusky, N. Malhotra, S. Westwood, The origins and consequences of affective polarization in the United States. Annu. Rev. of Political Sci, 22, 1, 129-146 (2019).

S. Iyengar, G. Sood, Y. Lelkes, Affect, not ideology: A social identity perspective on polarization. Public Opin Q., 76, 3, 405-431 (2012).

N. Kteily, E. Bruneau, Backlash: The politics and real-world consequences of minority group dehumanization. Pers. Soc. Psychol. Bull., 43, 1, 87-104 (2017).

N. Kteily, E. Bruneau, Darker demons of our nature: The need to (re)focus attention on blatant forms of dehumanization. Curr. Dir. Psychol. Sci., 26, 6, 487-494 (2017).

N. Kteily, E. Bruneau, A. Waytz, S. Cotterill, The ascent of man: Theoretical and empirical evidence for blatant dehumanization. J. Pers. Soc. Psychol, 109, 5, 901-931 (2015).

N. Kteily, G. Hodson, E. Bruneau, They see us as less than human: Metadehumanization predicts intergroup conflict via reciprocal dehumanization. J. Pers. Soc. Psychol, 110, 3, 343-370 (2016).

J. Lees, M. Cikara, Inaccurate group meta-perceptions drive negative out-group attributions in competitive contexts. Nat. Hum. Behav., 4, 279-286 (2020).

M. Levendusky, N. Malhotra, (Mis)perceptions of partisan polarization in the American public. Public Opin. Q., 80, S1, 378-391(2016). 
M. Levendusky, N. Malhotra, Does media coverage of partisan polarization affect political attitudes? Political Commun., 33, 2, 283-301 (2016).

Monmouth University, Americans feel divided on core values. Available at https://www.monmouth.edu/polling-institute/reports/monmouthpoll_us_101419/ (2019). Accessed on 3 January 2020.

S. L. Moore-Berg, B. Hameiri, E. Bruneau, The Prime Psychological Suspects of Toxic Political Polarization. Current Opinion in Behavioral Sciences (2020) In press.

T.C. O’Brien, B. Leidner, L.R. Tropp, Are they for us or against us? How intergroup metaperceptions shape foreign policy attitudes. Group Process. Intergr. Relat., 21, 6, 941-961 (2018).

R.J. Robinson, D. Keltner, A. Ward, L. Ross, Actual versus assumed differences in construal: "Naïve realism" in intergroup perception and conflict. J. Pers. Soc. Psychol., 68, 3, 404417 (1995).

D.K. Sherman, L.D. Nelson, L.D. Ross, Naïve realism and affirmative action: Adversaries are more similar than they think. Basic Appl. Soc. Psychol., 25, 4, 275-290 (2003).

D.L. Smith, Less than human: why we demean, enslave, and exterminate others. (St. Martin's Press, 2011).

M. Svolik, Polarization versus democracy. J. of Democr.,30, 3, 20-32 (2019).

J. Westfall, L. Van Boven, J.R. Chambers, C.M. Judd, Perceiving political polarization in the united states: Party identity strength and attitude extremity exacerbate the perceived partisan divide. Perspect. Psychol. Sci., 10, 2, 145-158 (2015). 
J.D. Vorauer, A.J. Hunter, K.J. Main, S.A. Roy. Meta-stereotype activation: Evidence from indirect measures for specific evaluative concerns experienced by members of dominant groups in intergroup interaction. J. Pers. Soc. Psychol, 78, 4, 690-707 (2000).

J.D. Vorauer, K.J. Main, G.B. O'Connell, How do individuals expect to be viewed by members of lower status groups? Content and implications of meta-stereotypes. J. Pers. Soc. Psychol, 75, 4, 917-937 (1998). 


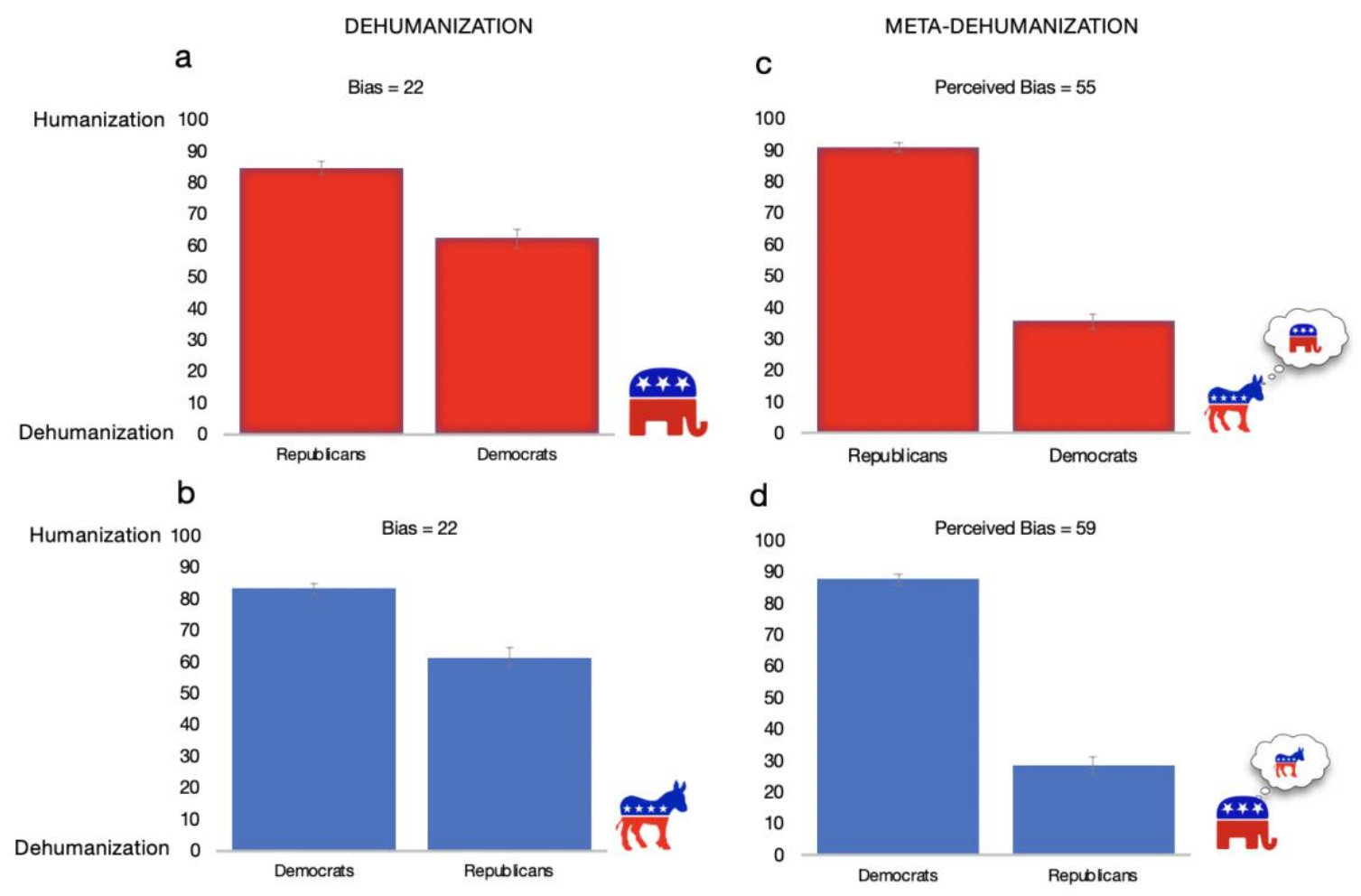

Figure 1. Study 1 dehumanization and meta-dehumanization reported by a representative sample of political partisans. Donkey $=$ Democrats; Elephant $=$ Republicans; Red bars $=$ responses/perceived responses by Republicans; Blue bars = responses/perceived responses by Democrats. a, b: humanity ratings of both target groups reported by Republicans (a) and Democrats (b), and ingroup-outgroup bias (i.e., 'dehumanization'); c, d: levels of humanity each group thought the other would report toward both target groups, and the perceived bias (i.e., 'meta-dehumanization'): how Democrats thought Republicans would respond (c), and how Republicans thought Democrats would respond (d). Error bars represent 95\% confidence intervals. 

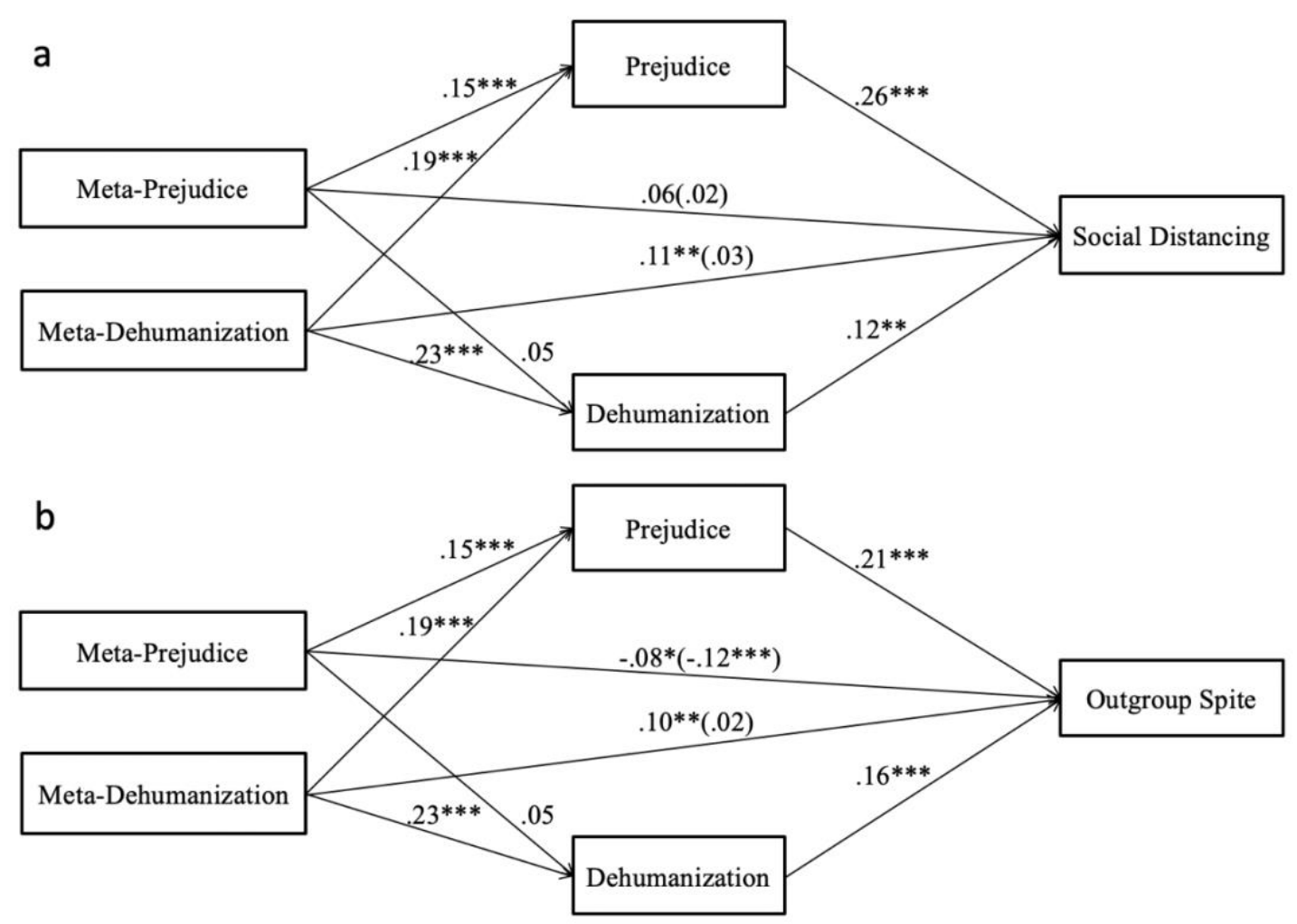

Figure 2. Study 1 path model examining perceptions among American participants, showing the link between feeling dehumanized and disliked by the other political party (metadehumanization, meta-prejudice) and supporting (a) social distancing and (b) outgroup spite via dehumanization of and prejudice toward the outgroup political party; standardized coefficients; ${ }^{\dagger} p<.10 ; * p<.05 ; * * p<.01 ; * * * p<.001$ 


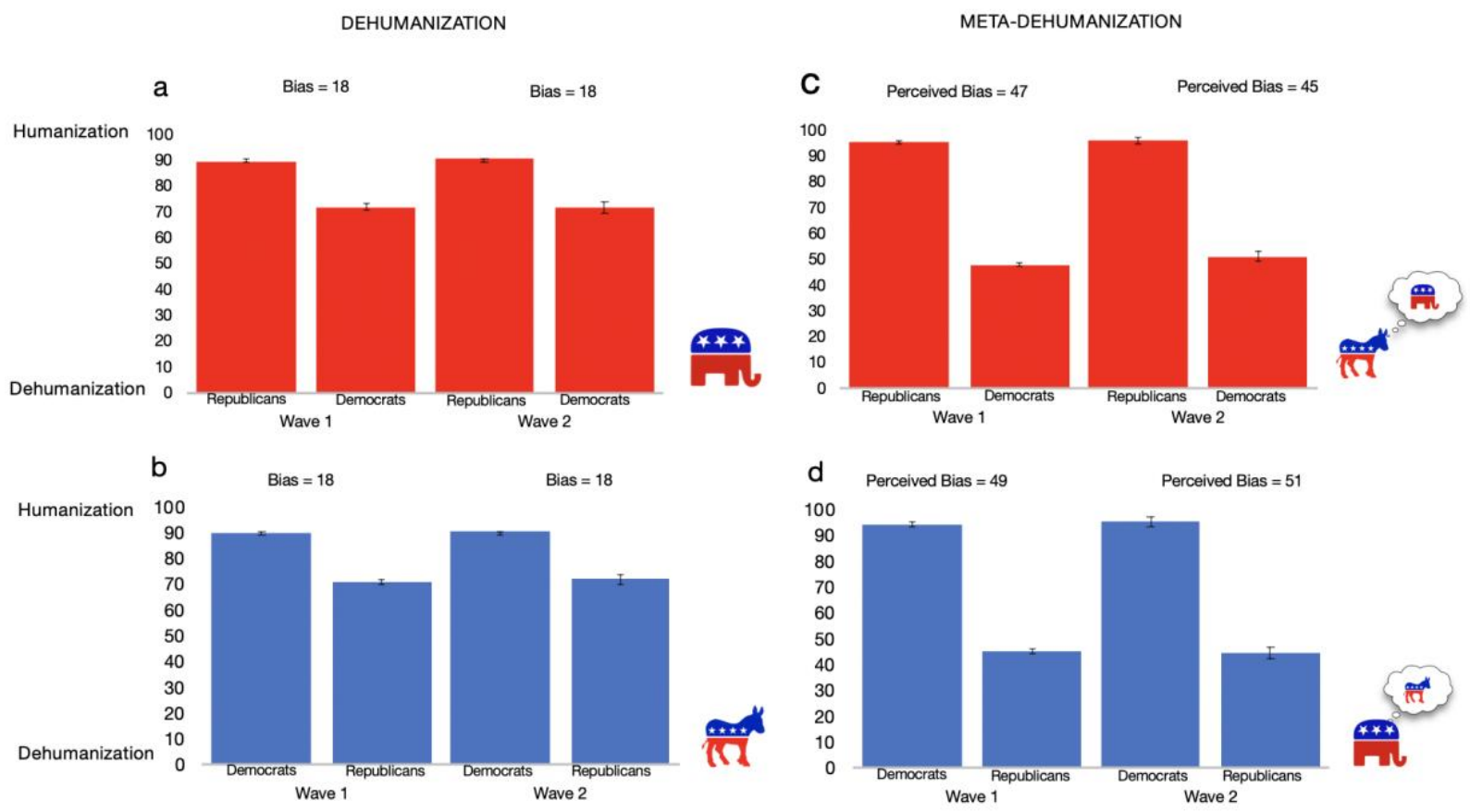

Figure 3. Study 2 dehumanization and meta-dehumanization reported by a sample of political partisans at two waves. Donkey $=$ Democrats; Elephant $=$ Republicans; Red bars $=$ responses/perceived responses by Republicans; Blue bars = responses/perceived responses by Democrats. a, b: humanity ratings of both target groups reported by Republicans (a) and Democrats (b), and ingroup-outgroup bias (i.e., 'dehumanization'); c, d: levels of humanity each group thought the other would report toward both target groups, and the perceived bias (i.e., 'meta-dehumanization'): how Democrats thought Republicans would respond (c), and how Republicans thought Democrats would respond (d). Error bars represent 95\% confidence intervals. 

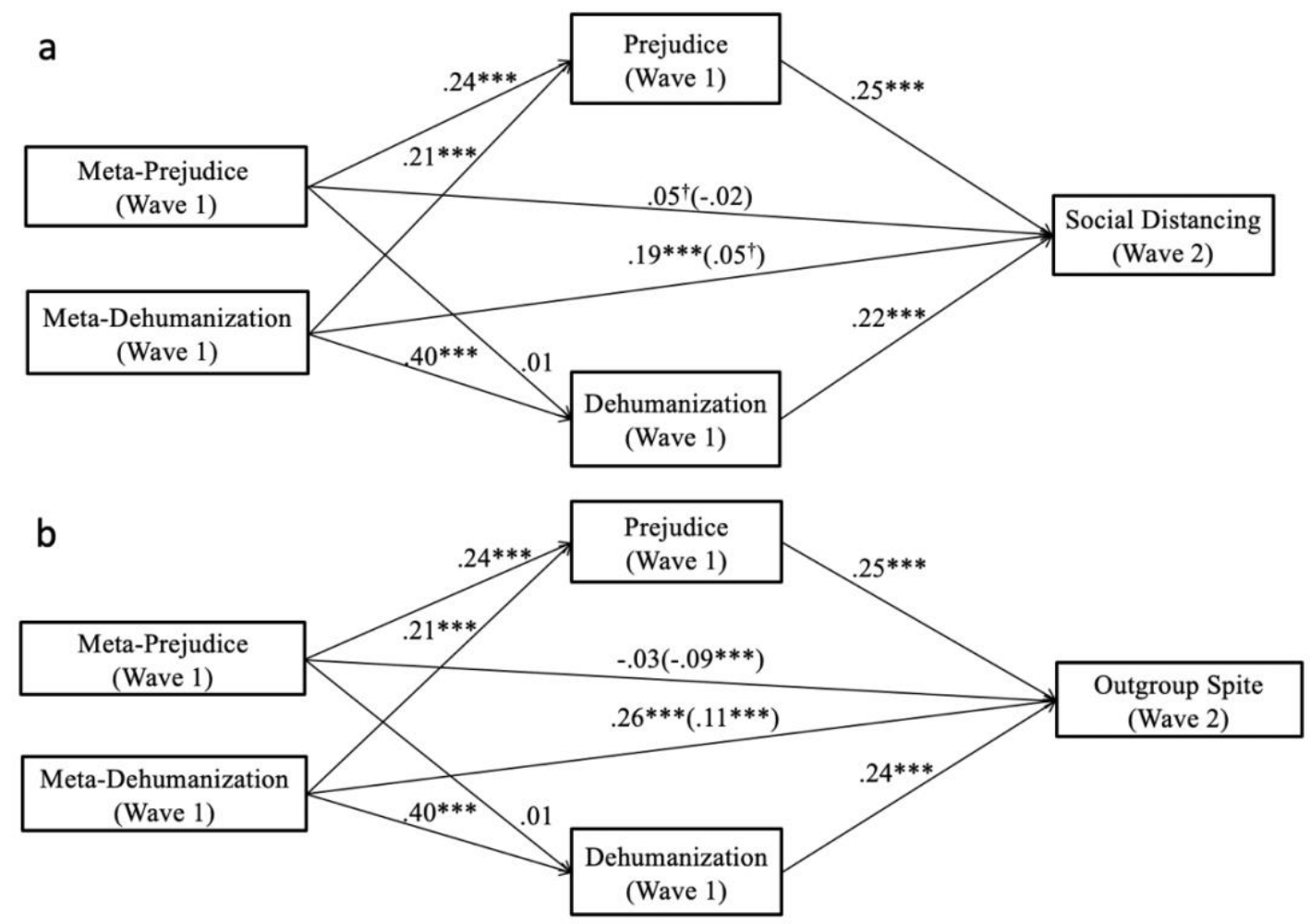

Figure 4. Study 2, path model examining perceptions among American political partisans, showing the link between feeling dehumanized by the other political party, assessed in Wave 1, and supporting (a) social distancing and (b) outgroup spite, both assessed in Wave 2, via dehumanization of and prejudice toward the other political party, both assessed in Wave 1; standardized coefficients; $\uparrow \mathrm{p}<.10 ; * \mathrm{p}<.05 ; * * \mathrm{p}<.01 ; * * * \mathrm{p}<.001$ 
Table 1. Study 1 descriptive statistics and variable intercorrelations for a representative sample of Democrats (A) and Republicans (B).

\section{A. Democrats}

\begin{tabular}{llccccc}
\hline & 1 & 2 & 3 & 4 & 5 & 6 \\
\hline 1. Prejudice & - & & & & & \\
2. Dehumanization & $.57^{* * *}$ & - & & & & \\
3. Meta-Prejudice & $.25^{* * *}$ & $.10^{* *}$ & - & & & \\
4. Meta-Dehumanization & $.29^{* * *}$ & $.21^{* * *}$ & $.58^{* * *}$ & - & & \\
5. Social Distancing & $.38^{* * *}$ & $.28^{* * *}$ & $.20^{* * *}$ & $.21^{* * *}$ & - & \\
6. Outgroup Spite & $.20^{* * *}$ & $.17^{* * *}$ & $-.16^{* * *}$ & -.03 & $.28^{* * *}$ & - \\
\hline \multicolumn{1}{c}{$M$ 's } & & & & & \\
\hline & 45.13 & 21.75 & 66.14 & 55.48 & 43.20 & 2.84 \\
& 35.03 & 34.37 & 33.71 & 34.06 & 29.04 & 1.46 \\
\hline
\end{tabular}

B. Republicans

\begin{tabular}{|c|c|c|c|c|c|c|}
\hline & 1 & 2 & 3 & 4 & 5 & 6 \\
\hline 1. Prejudice & - & & & & & \\
\hline 2. Dehumanization & $.62 * * *$ & - & & & & \\
\hline 3. Meta-Prejudice & $.25 * * *$ & $.15^{* *}$ & - & & & \\
\hline 4. Meta-Dehumanization & $.31 * * *$ & $.29 * * *$ & $.58 * * *$ & - & & \\
\hline 5. Social Distancing & $.37 * * *$ & $.21 * * *$ & $.09 *$ & $.13 * *$ & - & \\
\hline 6. Outgroup Spite & $.34 * * *$ & $.31 * * *$ & -.04 & $.10^{*}$ & $.42 * * *$ & - \\
\hline$M$ & 42.19 & 22.28 & 70.56 & 59.37 & 40.04 & 2.88 \\
\hline$S D$ & 37.15 & 34.05 & 29.10 & 34.68 & 26.46 & 1.44 \\
\hline
\end{tabular}

Notes. $* p<.05, * * p<0.01, * * * p<.001$ 
Table 2. Standardized total, direct, and indirect effects of Meta-Dehumanization on Social Distancing and Outgroup Spite via Dehumanization and Prejudice in Study 1, controlling for Meta-Prejudice.

\begin{tabular}{lcc}
\hline & Social Distancing & Outgroup Spite \\
\hline Indirect effect (dehumanization) & $.03[.01, .05]$ & $.04[.02, .06]$ \\
Indirect effect (prejudice) & $.05[.03, .08]$ & $.04[.02, .07]$ \\
Direct effect & $.03[-.04, .10]$ & $.02[-.05, .09]$ \\
Total effect & $.11[.04, .18]$ & $.10[.03, .17]$ \\
\hline
\end{tabular}

Note. Brackets represent $95 \%$ confidence intervals. 
Table 3. Study 2 descriptive statistics and variable intercorrelations for a sample of Democrats (A) and Republicans (B) assessed at 2 waves.

A. Democrats

\begin{tabular}{|c|c|c|c|c|c|c|}
\hline & 1 & 2 & 3 & 4 & 5 & 6 \\
\hline 1. Prejudice & $.68 * * *$ & $.54 * * *$ & $.35 * * *$ & $.33 * * *$ & $.37 * * *$ & $.37 * * *$ \\
\hline 2. Dehumanization & $.49 * * *$ & $.59 * * *$ & $.24 * * *$ & $40 * * *$ & $.37 * * *$ & $.33 * * *$ \\
\hline 3. Meta-Prejudice & $.37 * * *$ & $.21 * * *$ & $.53 * * *$ & $.52 * * *$ & $.12 * * *$ & $.09 * * *$ \\
\hline 4. Meta-Dehumanization & $.27 * * *$ & $.39 * * *$ & $.50 * * *$ & $.57 * * *$ & $.21 * * *$ & $.20 * * *$ \\
\hline 5. Social Distancing & $.36 * * *$ & $.34 * * *$ & $.15^{* * *}$ & $.23 * * *$ & $.75 * * *$ & $.47 * * *$ \\
\hline 6. Outgroup Spite & $.31 * * *$ & $.36 * * *$ & $.15 * * *$ & $.26 * * *$ & $.47 * * *$ & $.78 * * *$ \\
\hline Wave $1 \underline{M s}$ & 42.01 & 18.36 & 69.01 & 47.26 & 39.00 & 3.73 \\
\hline Wave $1 \overline{S D} s$ & 34.66 & 30.00 & 31.11 & 35.66 & 30.01 & 1.30 \\
\hline Wave $2 M s$ & 40.73 & 18.19 & 66.81 & 44.89 & 38.94 & 3.60 \\
\hline Wave $2 S D$ s & 33.39 & 28.99 & 29.64 & 33.90 & 29.93 & 1.30 \\
\hline
\end{tabular}

\section{B. Republicans}

\begin{tabular}{|c|c|c|c|c|c|c|}
\hline & 1 & 2 & 3 & 4 & 5 & 6 \\
\hline 1. Prejudice & $.69 * * *$ & $.56 * * *$ & $.37 * * *$ & $.37 * * *$ & $.43 * * *$ & $.45 * * *$ \\
\hline 2. Dehumanization & $.61 * * *$ & $.68 * * *$ & $20 * * *$ & $.38 * * *$ & $41 * * *$ & $.47 * * *$ \\
\hline 3. Meta-Prejudice & $.37 * * *$ & $.25 * * *$ & $.60 * * *$ & $.56 * * *$ & $.12 * * *$ & $.10 * *$ \\
\hline $\begin{array}{l}\text { 4. Meta- } \\
\text { Dehumanization }\end{array}$ & $.40 * * *$ & $.42 * * *$ & $.54 * * *$ & $.59 * * *$ & $23 * * *$ & $.23 * * *$ \\
\hline 5. Social Distancing & $.45 * * *$ & $.47 * * *$ & $.20 * * *$ & $.31 * * *$ & $.75 * * *$ & $.55 * * *$ \\
\hline 6. Outgroup Spite & $.49 * * *$ & $.47 * * *$ & $.15^{* * *}$ & $.29 * * *$ & $.52 * * *$ & $.78 * * *$ \\
\hline Wave $1 \underline{M s}$ & 35.98 & 17.73 & 67.59 & 48.93 & 32.99 & 3.35 \\
\hline Wave 1 SDs & 36.07 & 30.78 & 32.60 & 37.33 & 28.85 & 1.35 \\
\hline Wave $2 M \mathrm{~s}$ & 38.21 & 18.42 & 68.32 & 50.61 & 33.48 & 3.39 \\
\hline Wave $2 S D$ s & 34.85 & 29.90 & 32.81 & 36.11 & 29.40 & 1.41 \\
\hline
\end{tabular}

Notes. Above the diagonal line in italics $=$ Wave 1, below the diagonal line $=$ Wave 2, on the diagonal line in bold $=$ Wave 1 correlation with the same Wave 2 variable; $* p<.05$, **p< $0.01, * * * p<.001$ 
Table 4. Standardized total, direct, and indirect effects of Meta-Dehumanization on Social Distancing and Outgroup Spite via Dehumanization and Prejudice in Study 2, controlling for MetaPrejudice.

\begin{tabular}{lcc}
\hline & Social Distancing & Outgroup Spite \\
\hline Indirect effect (dehumanization) & $.09[.06, .11]$ & $.10[.07, .12]$ \\
Indirect effect (prejudice) & $.05[.04, .07]$ & $.05[.04, .07]$ \\
Direct effect & $.05[-.002, .10]$ & $.11[.06, .16]$ \\
Total effect & $.19[.14, .24]$ & $.26[.20, .31]$ \\
\hline
\end{tabular}

Note. Brackets represent $95 \%$ confidence intervals. 


\section{Supplementary Information Text}

\section{Study 1: Sample Information}

Participants were recruited through the Amerispeak panel, which is operated by NORC at the University of Chicago. AmeriSpeak ${ }^{\circledR}$ is a probability-based panel designed to be representative of the U.S. household population. Randomly selected U.S. households are sampled using area probability and address-based sampling, with a known, non-zero probability of selection from the NORC National Sample Frame. The panel provides sample coverage of approximately $97 \%$ of the U.S. household population. Those excluded from the sample include people with P.O. Box only addresses, some addresses not listed in the USPS Delivery Sequence File, and some newly constructed dwellings. Most AmeriSpeak households participate in surveys by web. Households without conventional internet access but having web access via smartphones are allowed to participate in AmeriSpeak surveys by web. 


\section{Study 1: Ideological Polarization Methods and Results}

\section{Methods}

Ideological Polarization. We assessed ideological polarization by evaluating views on border policy with the following prompt: "Some think that we should welcome people to visit and work temporarily in the U.S., but that our borders should be closed to migrants who wish to immigrate here. Others think that there should be no border restrictions, and that anybody should be free to immigrate to the U.S. Many people fall somewhere in between these two extremes." Participants were then asked to provide their position using a sliding scale anchored at borders completely open to all migrants (0) to borders completely closed to all migrants (100). We reverse-coded scores for easier interpretation, such that higher scores indicate greater preference for borders completely open to all migrants. After providing their own responses, participants indicated how they thought Americans who identify as Republicans and those who identify as Democrats would respond on the same issue. We defined perceived ideological polarization as the absolute difference between how participants thought the ingroup would respond versus how they thought the outgroup would respond.

\section{Results}

Ideological Polarization. We examined ideological polarization on the issue of border policy. Relative to the midpoint of the ideological scale (midpoint $=50$ ), Democrats were more in favor of open borders $(M=61.06, S D=24.01 ; t(579)=11.10, p<.001, d=.46)$, and Republicans were more in favor of closed borders $(M=25.00, S D=21.94 ; t(471)=-24.77, p<$ $.001, d=1.14)$, with Democrats and Republicans differing significantly from each other $\left(M_{\text {diff }}=\right.$ $36.07 ; t(1050)=25.19, p<.001, d=1.57)$. We then turned to the key question and examined how well Democrats and Republicans estimates of each group's positions on the issue matched 
the actual views held by representative samples of each group. We found that the perceived ideological gap between Democrats and Republicans was nearly twice as great as the actual gap among both Democrats (perceived $M_{\text {diff }}=51.87, S D=34.43 ; t(582)=36.37, p<.001, d=1.51$ ) and Republicans (perceived $\left.M_{d i f f}=65.94, S D=31.25 ; t(471)=45.85, p<.001, d=2.11\right)$. (See Table S2 and Figure S2.)

We next examined the relationship between ideological polarization and outcomes. Since the ideological meta-perceptions (perceived ingroup position versus perceived outgroup position) were calculated differently than intergroup meta-perceptions (perceived difference between how outgroup evaluated outgroup versus ingroup), we therefore avoided directly comparing these measures, and instead conducted simple zero-order correlations to examine the relationship between perceived ingroup-outgroup gap in border policy and the outcome measures. Although Democrats and Republicans overestimated the ideological divide to a similar degree, the perceived difference between ingroup and outgroup on the ideological issue of borders was only associated with social distancing for Democrats and both outcomes for Republicans. (See Table S2.)

Comparison between meta-perceptions and ideological polarization. We then compared the proportions of partisans who overestimated meta-perceptions and ideological polarization (see Table S3). Even though the proportion of partisans who overestimated levels of outgroup prejudice and dehumanization was similar to the proportion of partisans who overestimated ideological polarization, meta-perceptions appeared to be more consistent and stronger predictors of the outcomes (see correlations in Table S2). 


\section{Study 1: Subgroup Results}

To gain a better understanding of which cohorts of partisans might be more or less susceptible to meta-perceptions or perceived ideological polarization, we examined whether subgroups (by race, gender, age, education, region, strength of party identification, and political ideology) of Democrats and Republicans were more or less prone to hold exaggerated metaperceptions or perceive high levels of ideological polarization (see Table S4).

To do this, we conducted the following analyses: For categorical variables of race (White, non-White), gender (male, female), education (high school or less, some college, BS or more), region (Northeast, Midwest, South, West), and strength of party identification (lean, weak, strong), we determined whether mean meta-perceptions or ideological polarization differed across subgroups using one-way ANOVAs (for region, education, strength of party identification) and $t$-tests (for race and gender); for continuous variables of age and ideology (liberal-conservative), we used correlation analyses.

Meta-Prejudice. For Democrats, meta-prejudice was consistent across ages $(r=.01, p=$ $.895)$, education levels $(F(2,578)=1.23, p=.292)$, regions (Democrats: $F(3,577)=.58, p=$ $.628)$ and strength of party identification $(F(2,578)=2.89, p=.056)$. However, Democrats' meta-prejudice was higher among Whites versus non-Whites $(t(580)=2.61, p=.009, d=.22)$ and men versus women $(t(580)=2.56, p=.011, d=.22)$.

Among Republicans, meta-prejudice was also consistent across ages $(r=-.01, p=.890)$, education levels $(F(2,462)=1.00, p=.367)$, regions $(F(3,461)=.89, p=.448)$, and strength of party identification $(F(2,462)=.71, p=.493)$; unlike with Democrats, Republicans' metaprejudice levels were similar for men and women $(t(464)=.98, p=.329, d=.09)$. As with 
Democrats, Republicans' meta-prejudice was higher for Whites versus non-Whites $(t(464)=$ 2.47, $p=.014, d=.30)$.

Meta-Dehumanization. For Democrats, meta-dehumanization was consistent across race $(t(574)=.88, p=.381, d=.07)$, ages $(r=-.02, p=.678)$, regions $(F(3,572)=.42, p=.737)$ and strength of party identification $(F(2,573)=1.15, p=.316)$. However, men held greater levels of meta-dehumanization than women $(t(574)=2.76, p=.006, d=.24)$, and metadehumanization varied across education levels $(F(2,573)=5.06, p=.007)$.

For Republicans, meta-dehumanization was consistent across gender $(t(458)=-.76, p=$ $.448, d=.07)$, education levels $(F(2,457)=.57, p=.568)$, and regions $(F(3,456)=.18, p=$ .914). However, Whites expressed greater meta-dehumanization than non-Whites $(t(458)=5.42$, $p<.001, d=.68)$, and meta-dehumanization also varied across ages $(r=.12, p=.014)$ and strength of party identification $(F(2,457)=4.07, p=.018)$.

Perceived Ideological Polarization. For Democrats, perceived ideological polarization was consistent across race $(t(581)=.29, p=.773, d=.02)$, gender $(t(581)=1.73, p=.085, d=$ $.15)$, education levels $(F(2,579)=.30, p=.743)$, and regions $(F(3,578)=.05, p=.986)$.

However, perceived ideological polarization varied across ages $(r=-.13, p=.002)$, strength of party identification $(F(2,579)=3.56, p=.029)$, and political ideology $(r=-.15, p=.001)$.

For Republicans, results were consistent across race $(t(470)=.86, p=.391, d=.11)$, gender $(t(470)=.83, p=.405, d=.08)$, education levels $(F(2,469)=1.47, p=.230)$, and regions $(F(3,468)=1.05, p=.369)$. However, perceived ideological polarization varied across ages $(r=$ $.10, p=.024)$, strength of party identification $(F(2,469)=6.63, p=.001)$, and political ideology $(r=.10, p=.043)$ 


\section{Study 2: Full Reporting of Meta-Perception Results from Main Text}

\section{Wave 1 Analyses}

Prejudice and Dehumanization. Republicans felt colder toward Democrats than Republicans $(t(1127)=33.50, p<.001, d=1.30)$ and denied humanity to Democrats more than Republicans $(t(1127)=19.35, p<.001, d=.66)$; at the same time, Democrats felt colder toward Republicans than Democrats $(t(1578)=48.17, p<.001, d=1.60)$, and denied humanity to Republicans more than Democrats $(t(1578)=24.32, p<.001, d=.68)$. Dehumanization was similar for Democrats and Republicans $(t(2705)=.53, p=.596, d=.02)$, while Democrats expressed slightly more prejudice than Republicans $(t(2705)=4.39, p<.001, d=.17)($ See Figure 3 for dehumanization \& Figure S3 for prejudice).

Meta-Prejudice and Meta-Dehumanization. Next, we examined meta-perceptions across both groups. As predicted, Democrats thought that Republicans feel colder toward Democrats than Republicans $(t(1577)=88.11, p<.001, d=3.41)$, and thought that Republicans deny humanity to Democrats more than Republicans $(t(1577)=52.64, p<.001, d=1.83)$. At the same time, Republicans thought that Democrats feel colder toward Republicans than Democrats $(t(1127)=69.62, p<.001, d=3.16)$, and thought that Democrats deny humanity to Republicans more than Democrats $(t(1127)=44.03, p<.001, d=1.82)$ (See Figure 3 for metadehumanization \& Figure S3 for meta-prejudice). Democrats and Republicans did not differ from each other on levels of meta-prejudice $(t(2704)=1.15, p=.250, d=.04)$ or metadehumanization $(t(2704)=1.18, p=.237, d=.05)$.

Accuracy of Meta-Perceptions. To examine the accuracy of intergroup meta-perceptions, we compared the degree to which each group thought that the political outgroup disliked and dehumanized their ingroup to the actual ground truth levels of prejudice and dehumanization 
expressed by the political outgroup. Overall, Democrats overestimated the levels of prejudice and dehumanization that Republicans harbor toward Democrats: Democrat meta-prejudice versus Republican actual prejudice $(t(2704)=25.46, p<.001, d=.98)$, with $85 \%$ of Democrats numerically overestimating prejudice; Democrat meta-dehumanization versus Republican actual dehumanization $(t(2704)=22.46, p<.001, d=.89)$, with $72 \%$ of Democrats numerically overestimating dehumanization. In fact, Democrats' estimates of prejudice and dehumanization held by the "average Republican" were significantly higher than levels of prejudice and dehumanization expressed even by those who identified most strongly as Republicans (prejudice: $t(1933)=7.31, p<.001, d=.40$; dehumanization: $t(1933)=8.17, p<.001, d=.48)$. Results were similar when we compared Democrat meta-perceptions from the mTurk sample in Study 2 to actual Republican perceptions from the representative sample in Study 1 (prejudice: $M_{\text {diff }}=$ $26.82 ; t(2040)=15.59, p<.001, d=.78 ;$ dehumanization: $M_{\text {diff }}=24.98 ; t(2038)=13.37, p<$ $.001, d=.72)$

Republicans similarly overestimated Democrats' levels of prejudice and dehumanization: Republican meta-prejudice versus Democrat actual prejudice $(t(2705)=19.40, p<.001, d=.76)$, with $79 \%$ of Republicans numerically overestimating prejudice; Republican metadehumanization versus Democrat actual dehumanization $(t(2705)=23.59, p<.001, d=.90)$, with $71 \%$ of Republicans numerically overestimating dehumanization. Again, Republicans' estimates of prejudice and dehumanization held by the "average Democrat" were significantly higher than prejudice and dehumanization expressed even by the most strongly identified Democrats (prejudice: $t(1737)=4.24, p<.001, d=.21$; dehumanization: $t(1737)=11.66, p<$ $.001, d=.59)$. Republican meta-perceptions were also far greater than Democrats' actual 
perceptions from the representative sample in Study 1 (prejudice: $M_{\text {diff }}=22.46 ; t(1704)=13.13$, $p<.001, d=.66$; dehumanization: $\left.M_{\text {diff }}=27.18 ; t(1707)=14.65, p<.001, d=.76\right)$.

\section{Wave 2 Analyses}

Prejudice and Dehumanization. Perceptions at Wave 2 were consistent with those at Wave 1: Republicans felt colder toward Democrats than Republicans $(t(793)=30.90, p<.001, d$ $=1.41)$ and denied humanity to Democrats more than Republicans $(t(793)=17.37, p<.001, d=$ $.71)$; at the same time, Democrats felt colder toward Republicans than Democrats $(t(1114)=$ $40.74, p<.001, d=1.55)$, and denied humanity to Republicans more than Democrats $(t(1114)=$ 20.95, $p<.001, d=.69$ ) (See Figure 3 for dehumanization and Figure S3 for prejudice). The difference between ingroup and outgroup on prejudice and dehumanization was equivalent for Democrats and Republicans $(t(1907)=1.60, p=.111, d=.07$ and $t(1907)=.18, p=.861, d=$ .01 , respectively)

Meta-Prejudice and Meta-Dehumanization. Meta-perceptions in Study 2 Wave 2 were also similar to Wave 1 and to Study 1: Democrats thought that Republicans feel colder toward Democrats than Republicans $(t(1114)=75.27, p<.001, d=3.33)$, and thought that Republicans deny humanity to Democrats more than Republicans $(t(1114)=44.22, p<.001, d=1.80)$. At the same time, Republicans thought that Democrats feel colder toward Republicans than Democrats $(t(793)=58.67 p<.001, d=3.25)$, and thought that Democrats deny humanity to Republicans more than Democrats $(t(793)=39.50, p<.001, d=1.95)$ (see Figure 3 for meta-dehumanization and Figure S3 for meta-prejudice). Democrats and Republicans did not differ from each other on levels of meta-prejudice $(t(1907)=1.04, p=.297, d=.05)$, but Republicans thought that they were dehumanized more by Democrats than Democrats thought they were dehumanized by Republicans $(t(1907)=3.53, p<.001, d=.16)$. 
Accuracy of Meta-Perceptions. To examine the accuracy of intergroup meta-perceptions, we compared the degree to which each group thought that the political outgroup disliked and dehumanized their ingroup to the actual ground truth levels of prejudice and dehumanization expressed by the political outgroup. Overall, Democrats overestimated the levels of prejudice and dehumanization that Republicans harbor toward Democrats: Democrat meta-prejudice versus Republican actual prejudice $(t(1907)=19.30, p<.001, d=.88)$, with $84 \%$ of Democrats numerically overestimating levels of prejudice; Democrat meta-dehumanization versus Republican actual dehumanization $(t(1907)=17.65, p<.001, d=.88)$, with $71 \%$ of Democrats numerically overestimating dehumanization. In fact, Democrats' estimates of prejudice and dehumanization held by the "average Republican" were significantly higher than levels of prejudice and dehumanization expressed even by those who identified most strongly as Republicans (prejudice: $t(1383)=4.13, p<.001, d=.27$; dehumanization: $t(1383)=6.79, p<$ $.001, d=.46)$. When comparing Democrat meta-perceptions to actual Republican perceptions from the representative sample in Study 1, the same pattern of effects appeared (prejudice: $M_{\text {diff }}$ $=26.62 ; t(1577)=13.92, p<.001, d=.73$; dehumanization: $M_{\text {diff }}=22.61 ; t(1575)=12.04, p<$ $.001, d=.67)$.

Republicans similarly overestimated Democrats' levels of prejudice and dehumanization: Republican meta-prejudice versus Democrat actual prejudice $(t(1907)=17.92, p<.001, d=.83)$, with $81 \%$ of Republicans numerically overestimating prejudice; Republican metadehumanization versus Democrat actual dehumanization $(t(1907)=21.72, p<.001, d=.99)$, with $73 \%$ of Republicans numerically overestimating dehumanization. Again, Republicans' estimates of prejudice and dehumanization expressed by the "average Democrat" were significantly higher than prejudice and dehumanization expressed even by the most strongly 
identified Democrats (prejudice: $t(1236)=5.18, p<.001, d=.31$; dehumanization: $t(1236)=$ 11.23, $p<.001, d=.67)$. Results were similar when comparing Republican meta-perceptions to ground truth Democrat perceptions from the representative sample in Study 1 (prejudice: $M_{\text {diff }}=$ $23.19 ; t(1370)=12.56, p<.001, d=.68$; dehumanization: $M_{\text {diff }}=28.86 ; t(1373)=14.94, p<$ $.001, d=.82)$ 


\section{Study 2: Ideological Polarization Methods and Results \\ Methods}

Ideological Polarization. In Study 2, we used the same ideological issue as in Study 1 (border policy) and added two additional ideological issues: gun policy and police culpability for a shooting. In order to directly compare the same issue of border policy across both studies, we analyzed each policy item separately.

We assessed gun policy with the following prompt: "Some people think that the $2^{\text {nd }}$ Amendment should be repealed, or that it was not intended to apply to citizens, and that guns should be outlawed in the United States. Other people think that the $2^{\text {nd }}$ Amendment protects a citizen's right to arms, and that there should be no regulation on guns whatsoever. Many people fall somewhere in between these two extremes-believing that Americans have a right to have weapons, but that there should be some regulations on firearms in the U.S." Participants were then asked to provide their position using a sliding scale anchored at repeal the $2^{\text {nd }}$ Amendment and outlaw guns (0) and there should be no restrictions on gun ownership (100). Just like in Study 1, we reverse-coded scores such that higher scores indicate greater preference for repealing the $2^{\text {nd }}$ Amendment and outlawing guns. Participants then rated how they thought Democrats and Republicans would respond on this issue.

We assessed police culpability with the following prompt that was about a specific event: “At 7:36 p.m. on September 16, 2016, Tulsa police received a 9-1-1 call about an abandoned vehicle. One caller said: 'There is a car that looks like somebody just jumped out of it and left it in the center of the road on $36^{\text {th }}$ Street North and North Lewis Avenue. It's dead in the middle of the street. It's a Navigator. The driver-side door is open like somebody jumped out. It's on the yellow line, blocking traffic. Nobody in the car.' Police arrived on the scene. Some minutes later, 
the owner of the vehicle — a black man named Terence Crutcher-was tased by a White police officer Tyler Turnbough and fatally shot by White police officer Betty Shelby. Mr. Crutcher was standing unarmed in the middle of the street during the encounter. Mr. Crutcher was a 40-yearold black man who was involved in his church and sang in the choir. Mr. Crutcher had also previously served five years in prison for selling crack cocaine. Police stated that Mr. Crutcher kept reaching into his pocket, refused to show his hands, walked toward his vehicle despite being told to stop, and then angled toward and reached into his vehicle. Critics have disputed this, as video and photographic evidence seems to show Crutcher's blood streaking the driver's side window from top to bottom after the shooting, indicating that it was closed. Shortly before the shooting, officers in the helicopter conversed with each other: 'This guy's still walking and isn't following commands. It's time for a taser, I think. I've got a feeling that's about to happen. That looks like a bad dude, too, could be on something.' Tulsa police chief Chuck Jordan said no weapon was recovered from Crutcher's body or vehicle. Toxicology reports found PCP in Crutcher's system.” Participants were then asked to provide their position using a sliding scale anchored at Officer Shelby entirely to blame (0) and Mr. Crutcher entirely to blame (100). We again reverse-coded scores such that higher scores indicate greater blame on Officer Shelby. Participants then rated how they thought Democrats and Republicans would respond on this issue.

\section{Results}

\section{Wave 1 Analyses - Ideological Polarization}

Border Policy. We examined ideological polarization on the issue of border policy. Relative to the midpoint of the ideological scale (midpoint $=50$ ), Democrats were in favor of open borders $(M=61.60, S D=25.05 ; t(1157)=18.40, p<.001, d=.46)$, and Republicans were 
in favor of closed borders $(M=29.01, S D=22.77 ; t(1127)=-30.96, p<.001, d=.92)$, with Democrats and Republicans differing significantly from each other $\left(M_{\text {diff }}=32.59 ; t(2704)=\right.$ $34.65, p<.001, d=1.36)$. We then turned to the key question and examined how well Democrats and Republicans estimates of each group's positions on the issue matched the actual views held by samples of each group. We found that the estimated ideological gap between Democrats and Republicans was nearly twice as great as the actual gap, among both Democrats $\left(\right.$ perceived $M_{\text {diff }}=59.83, S D=28.86 ; t(1577)=82.35, p<.001, d=2.07$ ) and Republicans (perceived $\left.M_{\text {diff }}=63.77, S D=31.44 ; t(1126)=68.08, p<.001, d=2.03\right) .($ See Table S5 and Figure S4.)

Gun Policy. Next, we examined ideological polarization on the issue of gun policy. Relative to the midpoint of the ideological scale (midpoint $=50$ ), Democrats favored repealing the $2^{\text {nd }}$ amendment and outlawing guns $(M=63.22, S D=26.52 ; t(1578)=19.80, p<.001, d=$ $.50)$, and Republicans favored no restriction on gun ownership $(M=30.52, S D=25.43 ; t(1127)$ $=-25.73, p<.001, d=.77$ ), with Democrats and Republicans differing significantly from each other $\left(M_{\text {diff }}=32.70 ; t(2705)=32.17, p<.001, d=1.26\right)$. We then turned to the key question and examined how well Democrats and Republicans estimates of each group's positions on the issue matched the actual views held by samples of each group. We found that the estimated ideological gap between Democrats and Republicans was nearly twice as great as the actual gap, among both Democrats (perceived $M_{\text {diff }}=59.15, S D=33.92 ; t(1578)=69.29, p<.001, d=1.74$ ) and Republicans (perceived $\left.M_{\text {diff }}=62.54, S D=36.09 ; t(1126)=58.17, p<.001, d=1.73\right)$. (See Table S5 and Figure S5.)

Police Culpability. Finally, we examined ideological polarization on the issue of police culpability. Relative to the midpoint of the ideological scale (midpoint $=50$ ), Democrats placed 
more blame on the police officer $(M=63.65, S D=27.27 ; t(1577)=19.88, p<.001, d=.50)$, and Republicans placed more blame on the Black civilian $(M=38.85, S D=27.05 ; t(1127)=-$ 13.85, $p<.001, d=.41$ ), with Democrats and Republicans differing significantly from each other $\left(M_{\text {diff }}=24.80 ; t(2704)=23.40, p<.001, d=.91\right)$. We then turned to the key question and examined how well Democrats' and Republicans' estimates of each group's position on the issues matched the actual views held by samples of each group. We found that the estimated ideological gap between Democrats and Republicans was nearly twice as great as the actual gap, among both Democrats (perceived $M_{\text {diff }}=54.76, S D=32.47 ; t(1577)=66.99, p<.001, d=1.69$ ) and Republicans (perceived $\left.M_{\text {diff }}=51.37, S D=35.56 ; t(1127)=48.52, p<.001, d=1.44\right)$. (See Table S5 and Figure S6.)

Outcomes. Then, we conducted zero-order correlations to examine the relationship between ideological polarization and outcomes. Although Democrats and Republicans overestimated the ideological divide to a similar degree, the perceived difference between ingroup and outgroup on perceived border control was only associated with social distancing and outgroup spite for Republicans. Perceived gun control was associated with social distancing for Democrats and Republicans; however, it was not associated with outgroup spite. Perceived police officer culpability was associated with social distancing for Democrats and Republicans, but with outgroup spite only among Democrats (see Table S5).

Comparison between meta-perceptions and ideological polarization. As in Study 1, we determined the proportion of partisans who overestimated meta-perceptions and ideological polarization. Overall rates of misperceptions ranged between 71-86\% (see Table S3). Even though meta-perceptions and ideological differences were similarly overestimated, meta- 
perceptions appeared to be more consistently and more strongly correlated with the outcomes (see Table S5).

\section{Wave 2 Analyses - Ideological Polarization}

Border policy. Relative to the midpoint of the ideological scale (midpoint $=50$ ),

Democrats were in favor of open borders $(M=63.40, S D=23.34 ; t(1114)=19.17, p<.001, d=$ $.57)$, and Republicans were in favor of closed borders $(M=29.23, S D=22.59 ; t(793)=-25.91, p$ $<.001, d=.92)$, with Democrats and Republicans differing significantly from each other $\left(M_{\text {diff }}=\right.$ 34.17; $t(1907)=31.95, p<.001, d=1.49)$. Consistent with Wave 1 and Study 1 , we found that the estimated ideological gap between Democrats and Republicans was nearly twice as great as the actual gap, among both Democrats (perceived $M_{\text {diff }}=59.33, S D=27.98 ; t(1113)=70.77, p<$ $.001, d=2.12$ ) and Republicans (perceived $M_{\text {diff }}=66.22, S D=27.67 ; t(793)=67.43, p<.001, d$ = 2.39). (See Table S5 and Figure S4.)

Gun Control. Relative to the midpoint of the ideological scale (50), Democrats favored repealing the $2^{\text {nd }}$ amendment and outlawing guns $(M=64.99, S D=25.17 ; t(1114)=19.88, p<$ $.001, d=.60)$, and Republicans favored no restriction on firearms $(M=29.49, S D=24.83$; $t(793)=-23.27, p<.001, d=.83)$, with Democrats and Republicans differing significantly from each other $\left(M_{\text {diff }}=35.49 ; t(1907)=30.54, p<.001, d=1.42\right)$. However, as with border policies, the estimated ideological gap between Democrats and Republicans was nearly twice as great as the actual gap, among both Democrats (perceived $M_{\text {diff }}=60.90, S D=30.52 ; t(1114)=66.63, p<$ $.001, d=2.00$ ) and Republicans (perceived $M_{\text {diff }}=66.26, S D=31.42 ; t(793)=59.43, p<.001, d$ = 2.11). (See Table S5 and Figure S5.)

Police Culpability. Relative to the scale midpoint (50), Democrats placed more blame on the police officer $(M=64.83, S D=27.11 ; t(1114)=18.27, p<.001, d=.55)$, and Republicans 
placed more blame on the Black civilian $(M=36.18, S D=27.00 ; t(793)=-14.42, p<.001, d=$ $.51)$, with Democrats and Republicans differing significantly from each other $\left(M_{\text {diff }}=28.65\right.$; $t(1907)=22.80, p<.001, d=1.06)$. Similar to the other two issues, we found that the estimated ideological gap between Democrats and Republicans was nearly twice as great as the actual gap, among both Democrats (perceived $M_{\text {diff }}=56.40, S D=30.82, t(1113)=61.08, p<.001, d=1.83$ ) and Republicans (perceived $\left.M_{d i f f}=55.37, S D=34.03, t(793)=45.84, p<.001, d=1.63\right)$. (See Table S5 and Figure S6.)

Outcomes. We then conducted zero-order correlations between Wave 2 ideological polarization and Wave 2 outcomes. As with Study 1 and Wave 1, although Democrats and Republicans overestimated the ideological divide to a similar degree, the perceived difference between ingroup and outgroup on border policy was only associated with outgroup spite for Republicans. However, perceived difference between Democrats and Republicans on gun control and police officer culpability were associated with both outcomes for Democrats, but were not associated with either outcome among Republicans (see Table S5).Therefore, in both studies, for all issues, Democrats and Republicans were in agreement that the ideological divide is approximately twice as great as it actually is; however, the degree to which estimated ideological polarization was associated with the outcomes was weak overall and variable across issues.

Comparison between meta-perceptions and ideological polarization. Overall the proportion of Democrats and Republicans who overestimated meta-prejudice, metadehumanization, or ideological polarization ranged from 71-88\% (see Table S3). Even though meta-perceptions and ideological polarization were overestimated to a similar degree and by a similar proportion of partisans, meta-perceptions appeared to be more consistent and stronger predictors of the outcomes (see Table S5). However, since the meta-perception and ideological 
polarization constructs were qualitatively distinct, all results comparing ideological and intergroup perceptions should be treated as suggestive only, and conclusions from these data should be tentative. 


\section{Study 2: Subgroup Results}

As in Study 1, in a final exploratory analysis, we examined whether subgroups (by race, gender, age, region, education, strength of party identification, and political ideology) of Democrats and Republicans held stronger or weaker meta-perceptions and/or perceived greater or less ideological polarization (see Table S4).

\section{Wave 1 Analyses}

Meta-Prejudice. For Democrats, results were consistent across race $(t(1576)=1.73, p=$ $.084, d=.09)$, ages $(r=.04, p=.079)$, education levels $(F(3,1575)=2.19, p=.112)$, and regions $(F(3,1571)=1.04, p=.372)$. However, women had higher meta-prejudice than men $(t(1570)=-3.20, p=.001, d=.16)$, and meta-prejudice varied by strength of party identification $(F(2,1575)=13.34, p<.001)$.

For Republicans, meta-prejudice results were consistent across gender $(t(1126)=-1.96, p$ $=.050, d=.12)$, education levels $(F(3,1125)=1.38, p=.253)$, regions $(F(3,1122)=2.24, p=$ $.082)$, and strength of party identification $(F(2,1125)=1.91, p=.149)$. However, Whites expressed more meta-prejudice than non-Whites $(t(1126)=3.51, p<.001, d=.27)$, and metaprejudice varied by age $(r=.14, p<.001)$.

Meta-Dehumanization. For Democrats, meta-dehumanization was consistent across race $(t(1576)=-.55, p=.583, d=.03)$, ages $(r=.04, p=.097)$, education levels $(F(2,1575)=1.96, p$ $=.141)$, and regions $(F(3,1571)=.53, p=.665)$. However, women expressed greater metadehumanization than men $(t(1570)=-2.11, p=.035, d=.11)$, and meta-dehumanization varied by strength of party identification $(F(2,1575)=10.75, p<.001)$

For Republicans, meta-dehumanization results were consistent across race $(t(1126)=$ $1.91, p=.056, d=.15)$, gender $(t(1126)=1.35, p=.178, d=.08)$, ages $(r=.04, p=.152)$, 
education levels $(F(2,1125)=2.73, p=.066)$, and regions $(F(3,1122)=.59, p=.624)$.

However, meta-dehumanization varied by strength of party identification $(F(2,1125)=4.43, p=$ $.012)$.

Perceived Ideological Polarization. We computed perceived ideological polarization as the average of the perceived border policy difference, perceived gun policy difference, and perceived police culpability difference.

For Democrats, perceived ideological polarization was consistent across race $(t(1575)=$ $.55, p=.546, d=.03)$, ages $(r=-.01, p=.744)$, education levels $(F(2,1574)=1.41, p=.244)$, and regions $(F(3,1570)=1.76, p=.152)$. However, women perceived greater ideological polarization than men $(t(1569)=4.26, p<.001, d=.21)$, and perceived ideological polarization varied by strength of party identification $(F(2,1574)=7.23, p=.001)$ and political ideology $(r=$ $-.32, p<.001)$

For Republicans, perceived ideological polarization were consistent across gender $(t(1124)=-1.21, p=.225, d=.07)$, education levels $(F(2,1123)=.71, p=.492)$, regions $(F(3$, $1120)=1.55, p=.201)$, and strength of party identification $(F(2,1123)=1.75, p=.174)$. However, perceived ideological polarization was greater for Whites than non-Whites $(t(1124)=$ $3.21, p=.001, d=.25)$, and perceived ideological polarization varied by age $(r=.06, p=.032)$ and political ideology $(r=.18, p<.001)$.

\section{Wave 2 Analyses}

Meta-Prejudice. For Democrats, meta-prejudice was consistent across ages $(r=.02, p=$ $.579)$, education levels $(F(2,1112)=.45, p=.638)$, and regions $(F(3,1111)=.19, p=.902)$. However, Whites expressed more meta-prejudice than non-Whites $(t(1113)=2.50, p=.013, d=$ 
$.16)$, and women expressed more meta-prejudice than men $(t(1109)=-2.59, p=.010, d=.16)$.

Meta-prejudice also varied by strength of party identification $(F(2,1112)=9.48, p<.001)$.

For Republicans, meta-prejudice was consistent across race $(t(792)=1.12, p=.264, d=$ $.11)$, gender $(t(792)=-1.35, p=.177, d=.10)$, education levels $(F(2,791)=1.08, p=.341)$, regions $(F(3,789)=.03, p=.995)$, and strength of party identification $(F(2,791)=2.52, p=$ $.081)$. However, meta-prejudice varied across ages $(r=.10, p=.003)$.

Meta-Dehumanization. For Democrats, there was not a significant difference in metadehumanization for race $(t(1113)=.22, p=.824, d=.01)$, gender $(t(1109)=-.80, p=.425, d=$ $.05)$, ages $(r=.02, p=.502)$, education levels $(F(2,1112)=2.94, p=.053)$, and regions $(F(3$, $1111)=.21, p=.887)$. However, meta-dehumanization varied by strength of party identification $(F(2,1112)=7.91, p=.001)$

For Republicans, meta-dehumanization results were consistent across race $(t(792)=1.46$, $p=.145, d=.14)$, gender (Republican: $t(792)=-.03, p=.978, d<.01)$, ages $(r=.01, p=.855)$, education levels $(F(2,791)=.72, p=.486)$, and regions $(F(3,789)=.07, p=.974)$. However, meta-dehumanization varied by strength of party identification $(F(2,791)=5.29, p=.005)$.

Perceived Ideological Polarization. For Democrats, perceived ideological polarization was consistent across race $(t(111)=1.48, p=.139, d=.10)$, ages $(r=-.03, p=.287)$, education levels $(F(2,1110)=1.39, p=.249)$, and regions $(F(3,789)=.07, p=.974)$. However, women perceived more ideological polarization than men $(t(1107)=-3.92, p<.001, d=.23)$. Perceived ideological polarization also varied by strength of party identification $(F(2,1110)=3.02, p=$ $.049)$ and political ideology $(r=-.25, p<.001)$.

For Republicans, perceived ideological polarization was consistent across ages $(r<.01$, $p=.906)$, education levels $(F(2,791)=1.30, p=.274)$, regions $(F(3,789)=.13, p=.941)$, 
strength of party identification $(F(2,791)=.81, p=.445)$, and political ideology $(r=.15, p=$ .794). However, Whites perceived greater ideological polarization than non-Whites $(t(792)=$ $3.31, p=.001, d=.31)$, and women perceived greater ideological polarization than men $(t(792)$ $=-2.14, p=.032, d=.15)$. 

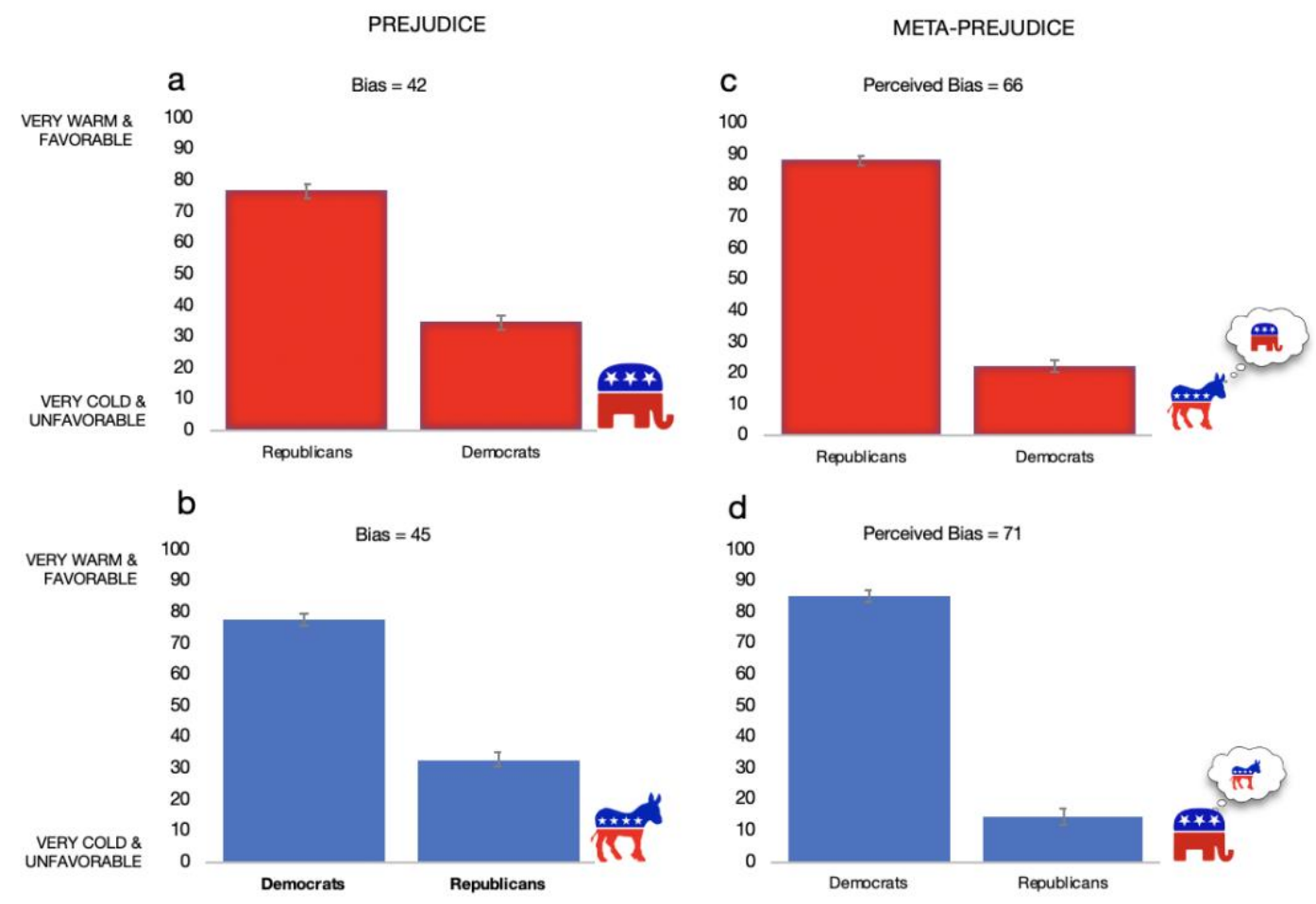

Figure S1. Study 1 prejudice and meta-prejudice reported by a representative sample of political partisans; Donkey = Democrats; Elephant = Republicans; Red bars $=$ responses/perceived responses by Republicans; Blue bars = responses/perceived responses by Democrats. a, b: warmth ratings of both target groups reported by Republicans (a) and Democrats (b), and ingroup-outgroup bias (i.e., 'prejudice'); c, d: levels of warmth each group thought the other would report toward both target groups, and the perceived bias (i.e., 'meta-prejudice'): how Democrats thought Republicans would respond (c), and how Republicans thought Democrats would respond (d). Error bars represent $95 \%$ confidence intervals. 


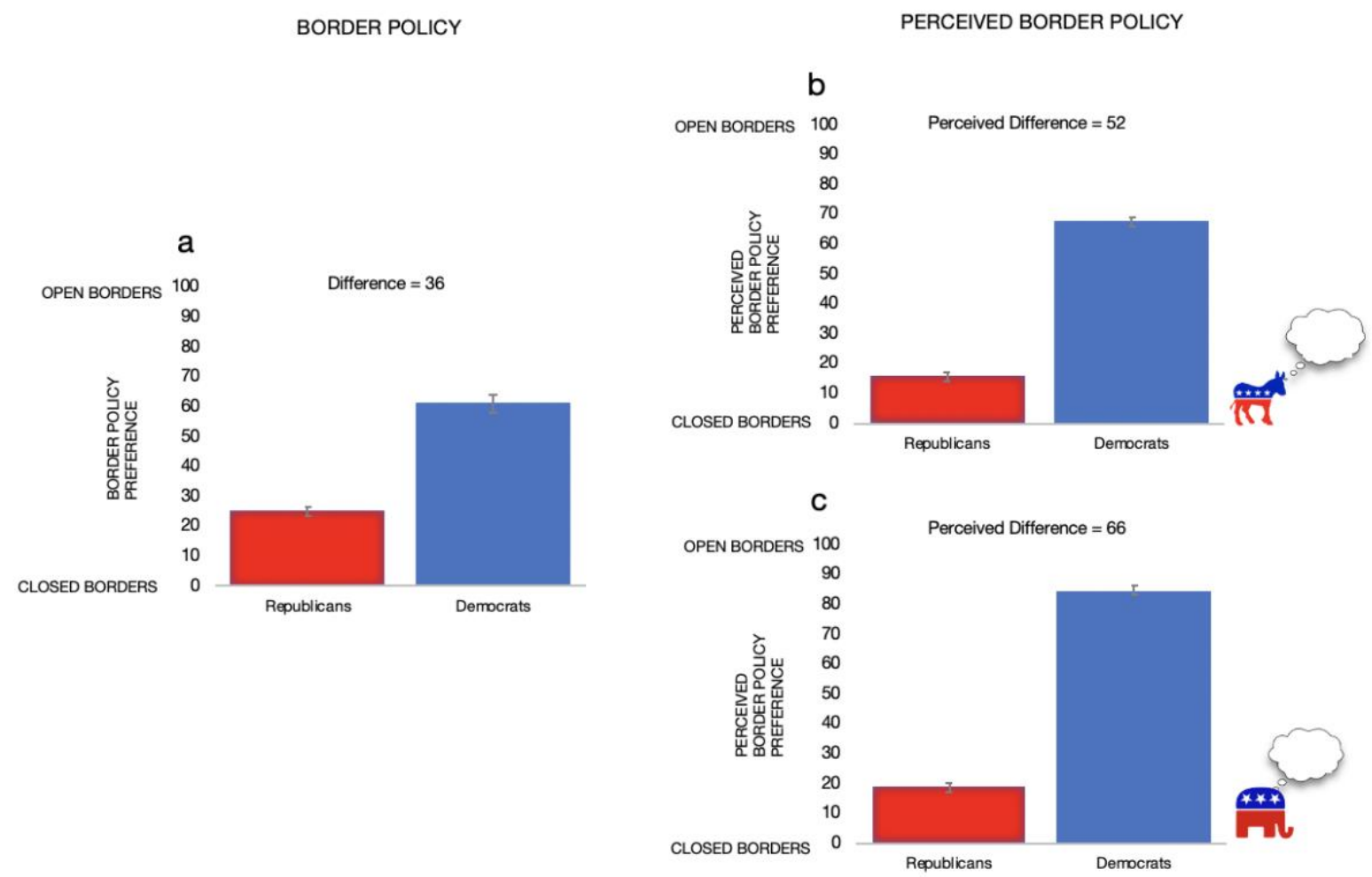

Figure S2. Study 1 ideological polarization reported by a representative sample of political partisans; Donkey = Democrats; Elephant = Republicans; Red bars = responses $/$ perceived responses by Republicans; Blue bars = responses/perceived responses by Democrats. a: border policy preference by Republicans and Democrats; b, c: perceived border policy preference that Democrats and Republicans thought their ingroup and outgroup would endorse; how Democrats thought Republicans and Democrats would respond (b), and how Republicans thought Republicans Democrats would respond (c). Error bars represent 95\% confidence intervals. 


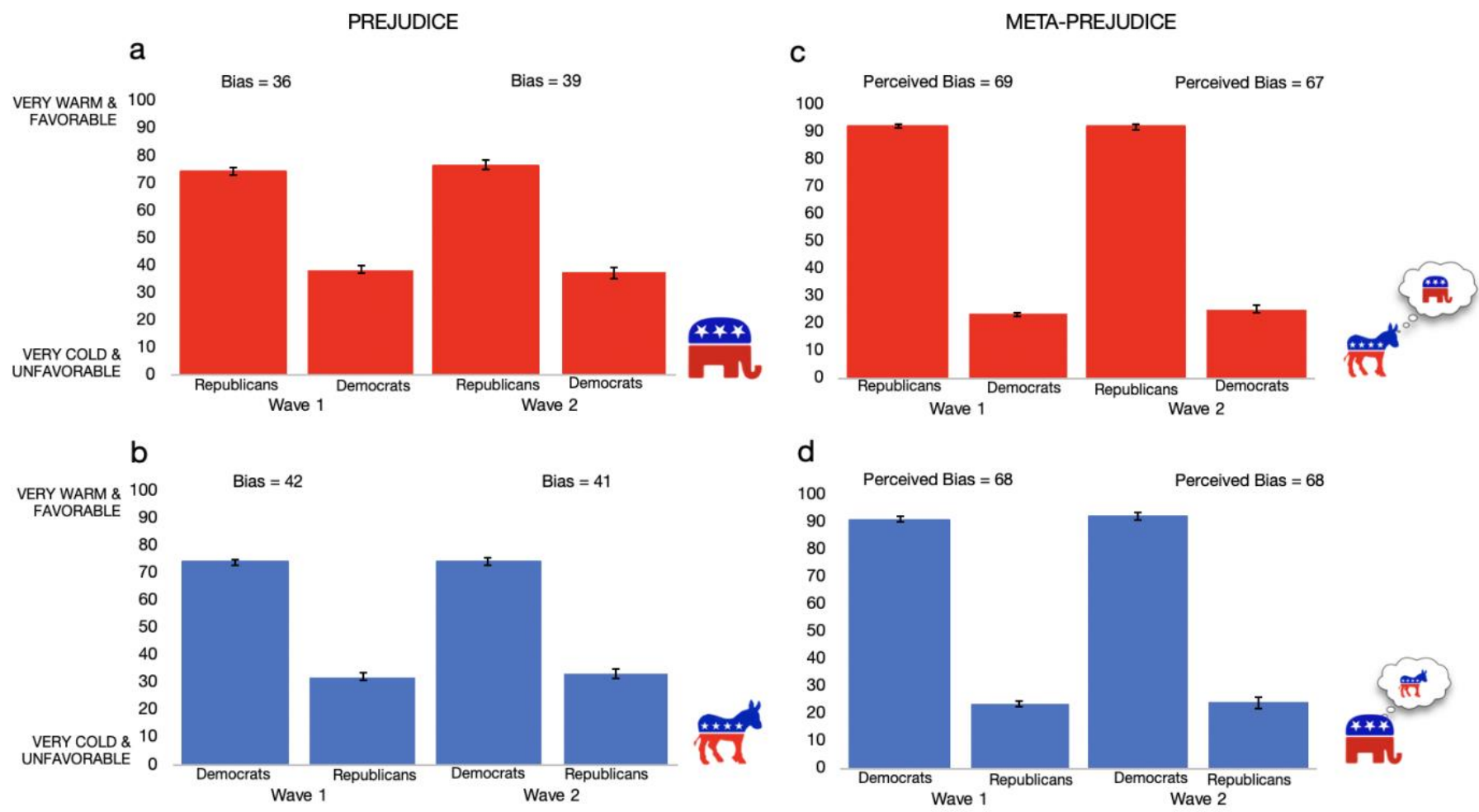

Figure S3. Study 2 prejudice and meta-prejudice reported by a sample of political partisans;

Donkey $=$ Democrats; Elephant $=$ Republicans; Red bars $=$ responses/perceived responses by Republicans; Blue bars = responses/perceived responses by Democrats. $\mathrm{a}, \mathrm{b}$ : warmth ratings of both target groups reported by Republicans (a) and Democrats (b), and ingroup-outgroup bias (i.e., 'prejudice'); c, d: levels of warmth each group thought the other would report toward both target groups, and the perceived bias (i.e., 'meta-prejudice'): how Democrats thought Republicans would respond (c), and how Republicans thought Democrats would respond (d). Error bars represent $95 \%$ confidence intervals. 


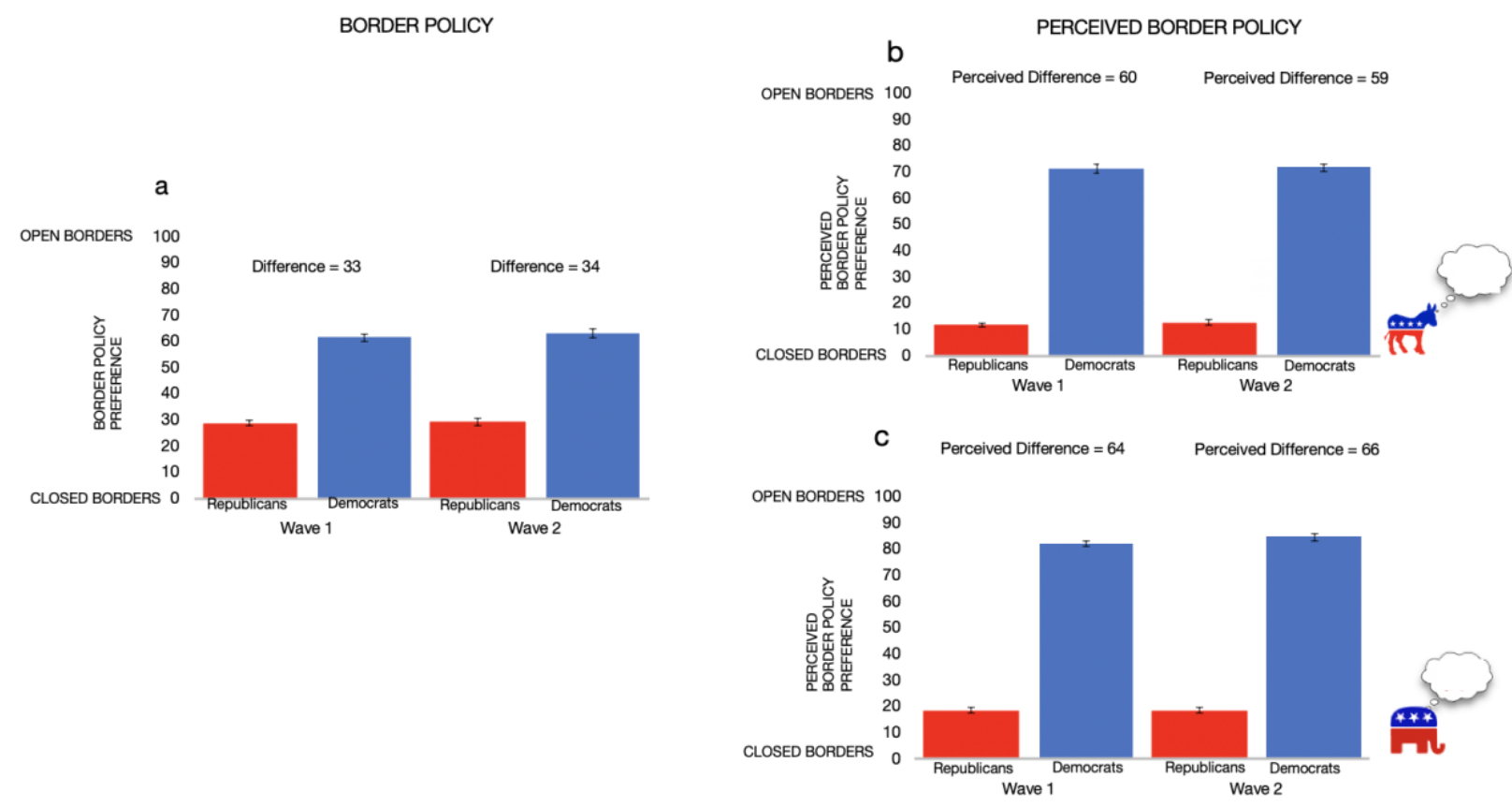

Figure S4. Study 2 ideological polarization and perceived polarization regarding border policy reported by political partisans; Donkey $=$ Democrats; Elephant $=$ Republicans; Red bars $=$ responses/perceived responses by Republicans; Blue bars = responses/perceived responses by Democrats. a: border policy preference by Republicans and Democrats; b, c: perceived border policy preference that Democrats and Republicans thought their ingroup and outgroup would endorse; how Democrats thought Republicans and Democrats would respond (b), and how Republicans thought Republicans and Democrats would respond (c). Error bars represent 95\% confidence intervals. 


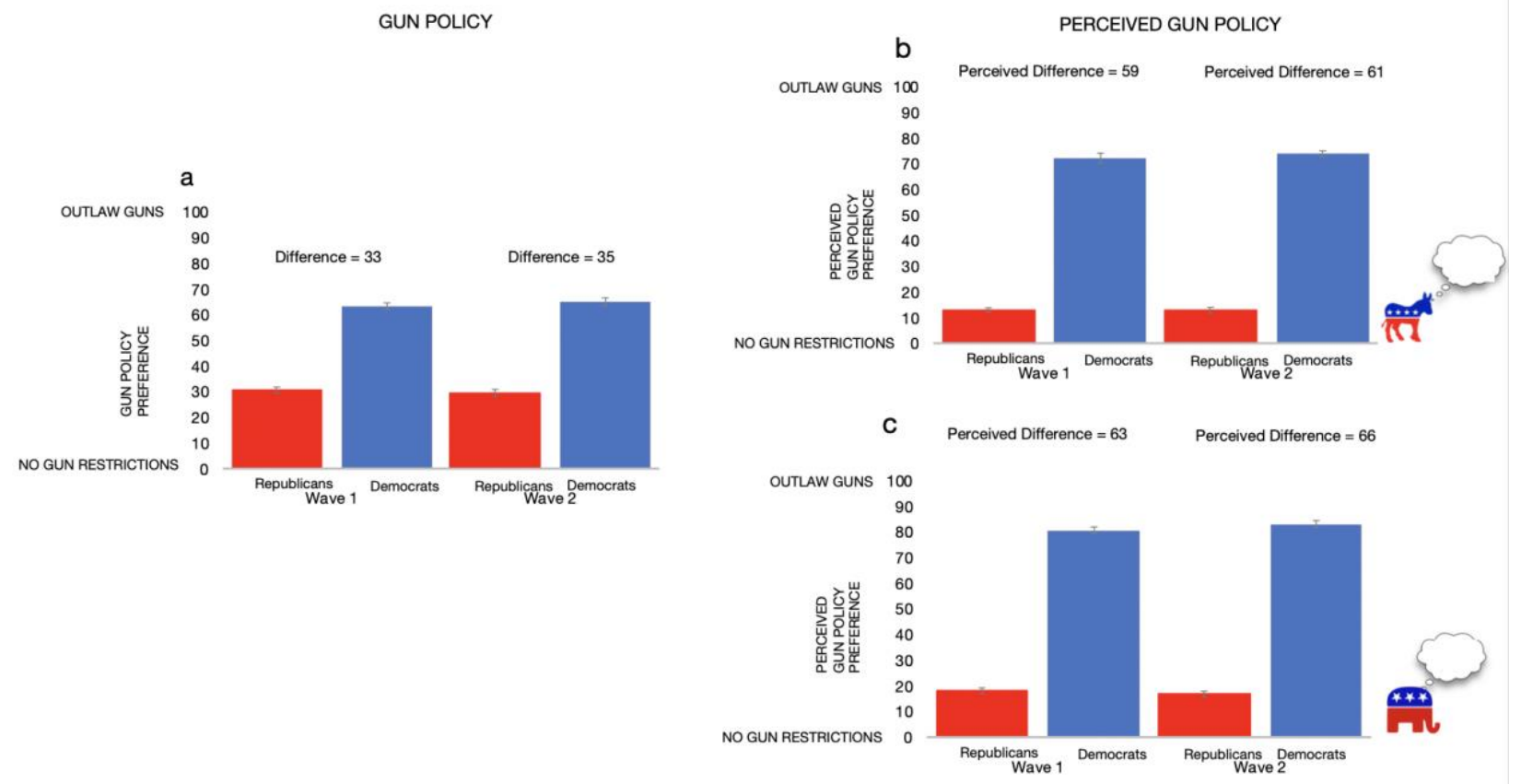

Figure S5. Study 2 ideological polarization and perceived polarization regarding gun policy reported by a sample of political partisans; Donkey = Democrats; Elephant = Republicans; Red bars $=$ responses/perceived responses by Republicans; Blue bars = responses/perceived responses by Democrats. a: gun policy preference by Republicans and Democrats; b, c: perceived gun policy preference that Democrats and Republicans thought their ingroup and outgroup would endorse; how Democrats thought Republicans and Democrats would respond (b), and how Republicans thought Republicans and Democrats would respond (c). Error bars represent 95\% confidence intervals. 


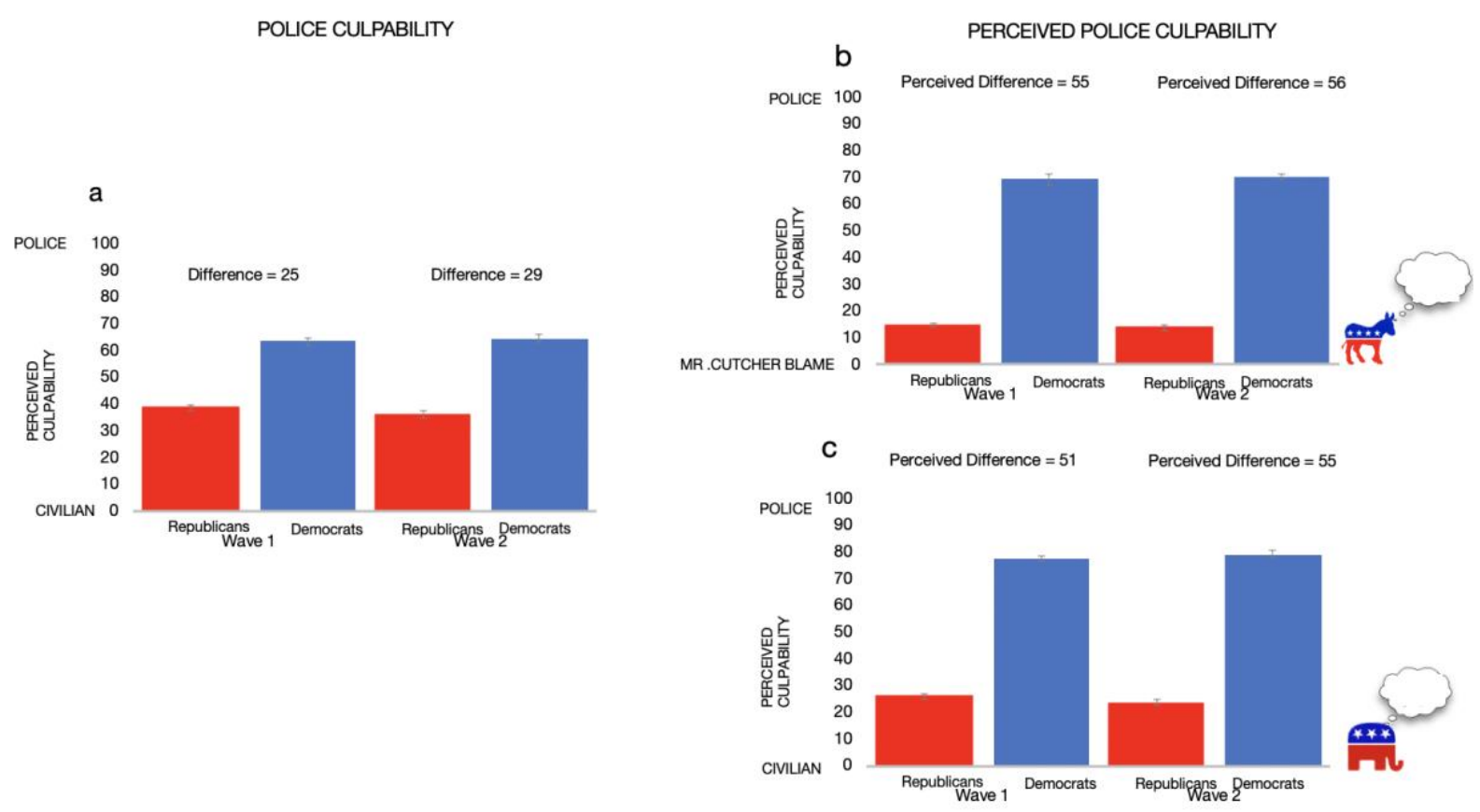

Figure S6. Study 2 ideological polarization and perceived polarization regarding police culpability reported by political partisans; Donkey $=$ Democrats; Elephant $=$ Republicans; Red bars $=$ responses/perceived responses by Republicans; Blue bars = responses/perceived responses by Democrats. a: police culpability preference by Republicans and Democrats; b, c: perceived police culpability preference that Democrats and Republicans thought their ingroup and outgroup would endorse; how Democrats thought Republicans and Democrats would respond (b), and how Republicans thought Republicans Democrats would respond (c). Error bars represent 95\% confidence intervals. 
Table S1. Comparison between Study demographics and benchmarks (Global Social Survey 2018)

\begin{tabular}{|c|c|c|c|c|c|}
\hline & $\begin{array}{c}\text { Study 1 } \\
\text { (Unweighted) }\end{array}$ & $\begin{array}{c}\text { Study } 1 \\
\text { (Weighted) }\end{array}$ & $\begin{array}{c}\text { Study } 2 \\
\text { (Wave 1) }\end{array}$ & $\begin{array}{c}\text { Study } 2 \\
\text { (Wave 2) }\end{array}$ & GSS 2018 \\
\hline \multicolumn{6}{|l|}{ Race (\%) } \\
\hline $\begin{array}{l}\text { Non-Hispanic } \\
\text { White }\end{array}$ & $72.6 \%$ & $65.9 \%$ & $76.1 \%$ & $76.7 \%$ & $66.1 \%$ \\
\hline $\begin{array}{l}\text { Non-Hispanic } \\
\text { Black }\end{array}$ & $11.4 \%$ & $14.7 \%$ & $8.8 \%$ & $8.1 \%$ & $15.3 \%$ \\
\hline Hispanic & $9.6 \%$ & $15.3 \%$ & $5.9 \%$ & $6.3 \%$ & $14.5 \%$ \\
\hline $\begin{array}{l}\text { Non-Hispanic } \\
\text { Other }\end{array}$ & $6.4 \%$ & $4.1 \%$ & $9.2 \%$ & $8.9 \%$ & $4.1 \%$ \\
\hline \multicolumn{6}{|l|}{ Gender (\%) } \\
\hline Male & $46.4 \%$ & $46.2 \%$ & $46.8 \%$ & $47 \%$ & $46.3 \%$ \\
\hline Female & $53.6 \%$ & $53.8 \%$ & $53 \%$ & $52.8 \%$ & $53.7 \%$ \\
\hline \multicolumn{6}{|l|}{ Age } \\
\hline $18-34$ & $24.9 \%$ & $29.4 \%$ & $45.7 \%$ & $40.3 \%$ & $28.1 \%$ \\
\hline $35-49$ & $24.9 \%$ & $24.7 \%$ & $34.7 \%$ & $37.8 \%$ & $26 \%$ \\
\hline $50-64$ & $28.5 \%$ & $25.9 \%$ & $15.7 \%$ & $17.4 \%$ & $25.9 \%$ \\
\hline $65+$ & $21.7 \%$ & $19.9 \%$ & $3.7 \%$ & $4.5 \%$ & $20 \%$ \\
\hline \multicolumn{6}{|l|}{$\begin{array}{l}\text { Regional } \\
\text { Breakdown (\%) }\end{array}$} \\
\hline Northeast & $14.8 \%$ & $17.7 \%$ & $17.8 \%$ & $16.7 \%$ & $17.6 \%$ \\
\hline Midwest & $27.2 \%$ & $22.4 \%$ & $20.2 \%$ & $21.3 \%$ & $22.4 \%$ \\
\hline South & $33.9 \%$ & $37.6 \%$ & $39.5 \%$ & $38.7 \%$ & $37.6 \%$ \\
\hline West & $24.1 \%$ & $22.3 \%$ & $22.3 \%$ & $23.3 \%$ & $22.4 \%$ \\
\hline
\end{tabular}

Notes. Study 1 (Weighted): $N=1056 ;$ Study 1 (Unweighted): $N=1053 ;$ Study 2, Wave 1: $N=2707$, Wave 2: $N=1909$. 
Table S2. Study 1 descriptive statistics and variable intercorrelations for a representative sample of Democrats (A) and Republicans (B).

\section{A. Democrats}

\begin{tabular}{|c|c|c|c|c|c|c|c|}
\hline & 1 & 2 & 3 & 4 & 5 & 6 & 7 \\
\hline 1. Prejudice & - & & & & & & \\
\hline 2. Dehumanization & $.57 * * *$ & - & & & & & \\
\hline 3. Meta-Prejudice & $.25 * * *$ & $.10^{*}$ & - & & & & \\
\hline 4. Meta-Dehumanization & $.29 * * *$ & $.21 * * *$ & $.58 * * *$ & - & & & \\
\hline 5. Ideological Polarization & $.18 * * *$ & $.11 *$ & $.31 * * *$ & $.21 * * *$ & & & \\
\hline 6. Social Distancing & $.38 * * *$ & $.28 * * *$ & $.20 * *$ & $.21 * * *$ & $.08^{*}$ & - & \\
\hline 7. Outgroup Spite & $.20 * * *$ & $.17 * * *$ & $-.16 * * *$ & -.03 & -.03 & $.28 * * *$ & - \\
\hline$M$ & 45.13 & 21.75 & 66.14 & 55.48 & 51.87 & 43.20 & 2.84 \\
\hline$S D$ & 35.03 & 34.37 & 33.71 & 34.06 & 34.43 & 29.04 & 1.46 \\
\hline
\end{tabular}

\section{B. Republicans}

\begin{tabular}{|c|c|c|c|c|c|c|c|}
\hline & 1 & 2 & 3 & 4 & 5 & 6 & 7 \\
\hline 1. Prejudice & - & & & & & & \\
\hline 2. Dehumanization & $.62 * * *$ & - & & & & & \\
\hline 3. Meta-Prejudice & $.25 * * *$ & $.15^{* *}$ & - & & & & \\
\hline 4. Meta-Dehumanization & $.31 * * *$ & $.29 * * *$ & $.58 * * *$ & - & & & \\
\hline 5. Ideological Polarization & $.28 * * *$ & $.21 * * *$ & $.28 * * *$ & $.26 * * *$ & & & \\
\hline 6. Social Distancing & $.37 * * *$ & $.21 * * *$ & $.09 *$ & $.13 * *$ & $.13 * *$ & - & \\
\hline 7. Outgroup Spite & $.34 * * *$ & $.31 * * *$ & -.04 & $.10 *$ & $.12 * *$ & $.42 * * *$ & - \\
\hline$M$ & 42.19 & 22.28 & 70.56 & 59.37 & 65.94 & 40.04 & 2.88 \\
\hline$S D$ & 37.15 & 34.05 & 29.10 & 34.68 & 31.25 & 26.46 & 1.44 \\
\hline
\end{tabular}

Notes. $* p<.05, * * p<0.01, * * * p<.001$ 
Table S3. Percentage of Democrats (A) and Republicans (B) who overestimated actual mean levels of outgroup prejudice, outgroup dehumanization, and ideological polarization.

\section{A. Democrats}

\begin{tabular}{lccc}
\hline & Study 1 & Study 2 (Wave 1) & Study 2 (Wave 2) \\
\hline Meta-prejudice & $79 \%$ & $85 \%$ & $84 \%$ \\
Meta-dehumanization & $79 \%$ & $72 \%$ & $71 \%$ \\
Border Policy & $78 \%$ & $86 \%$ & $85 \%$ \\
Gun Policy & $\mathrm{n} / \mathrm{a}$ & $83 \%$ & $85 \%$ \\
Police Culpability & $\mathrm{n} / \mathrm{a}$ & $82 \%$ & $84 \%$ \\
\hline
\end{tabular}

\section{B. Republicans}

\begin{tabular}{lccc}
\hline & Study 1 & Study 2 (Wave 1) & Study 2(Wave 2) \\
\hline Meta-prejudice & $81 \%$ & $79 \%$ & $81 \%$ \\
Meta-dehumanization & $82 \%$ & $71 \%$ & $73 \%$ \\
Border Policy & $85 \%$ & $84 \%$ & $88 \%$ \\
Gun Policy & n/a & $83 \%$ & $86 \%$ \\
Police Culpability & n/a & $78 \%$ & $79 \%$ \\
\hline
\end{tabular}


Table S4. Means (and standard deviations) for meta-perceptions and perceived ideological polarization by demographic sub-groups for samples of Democrats (A) and Republicans (B).

\section{A. Democrats}

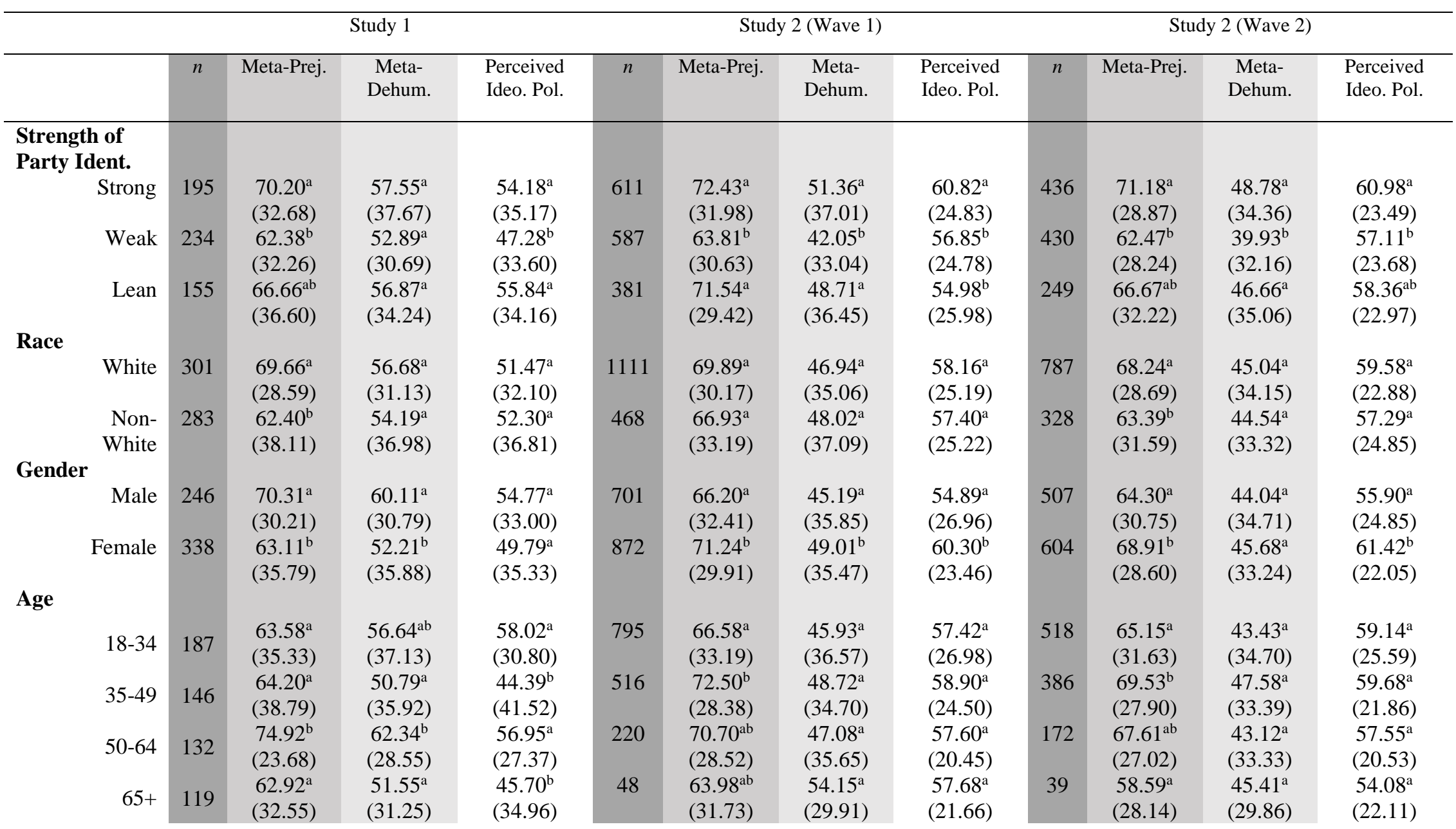




\begin{tabular}{|c|c|c|c|c|c|c|c|c|c|c|c|c|}
\hline & 105 & & & & 140 & & & & 08 & & & \\
\hline $\begin{array}{l}\text { Ho or } \\
\text { Below }\end{array}$ & 195 & $\begin{array}{l}05.10 \\
(36.15)\end{array}$ & $(36.61)$ & $(32.14)$ & 140 & $(36.68)$ & $\begin{array}{l}45.50 \\
(36.02)\end{array}$ & $\begin{array}{l}34.00 \\
(31.77)\end{array}$ & 90 & $\begin{array}{l}04.41 \\
(36.02)\end{array}$ & $(37.30)$ & $(30.44)$ \\
\hline Some & 159 & $69.42^{\mathrm{a}}$ & $56.66^{\mathrm{ab}}$ & $52.53^{a}$ & 508 & $69.87^{b}$ & $49.82^{a}$ & $58.59^{a}$ & 350 & $66.48^{a}$ & $44.61^{b}$ & $60.12^{a}$ \\
\hline College & & (33.87) & $(31.28)$ & (38.99) & & $(31.43)$ & $(35.07)$ & $(25.79)$ & & $(29.51)$ & $(32.35)$ & (21.93) \\
\hline $\mathrm{BA}+$ & 231 & $\begin{array}{c}65.90^{\mathrm{a}} \\
(31.35)\end{array}$ & $\begin{array}{c}50.35^{\mathrm{b}} \\
(33.10)\end{array}$ & $\begin{array}{c}52.73^{\mathrm{a}} \\
(33.03)\end{array}$ & 931 & $\begin{array}{l}69.32^{\mathrm{ab}} \\
(29.97)\end{array}$ & $\begin{array}{l}46.12^{\mathrm{a}} \\
(35.89)\end{array}$ & $\begin{array}{l}58.08^{\mathrm{a}} \\
(23.69)\end{array}$ & 667 & $\begin{array}{l}67.34^{\mathrm{a}} \\
(28.69)\end{array}$ & $\begin{array}{l}43.88^{b} \\
(34.07)\end{array}$ & $\begin{array}{l}58.74^{\mathrm{a}} \\
(23.10)\end{array}$ \\
\hline \multicolumn{13}{|l|}{ Region } \\
\hline Northeast & 124 & $\begin{array}{c}63.22^{\mathrm{a}} \\
(29.55)\end{array}$ & $\begin{array}{c}57.76^{a} \\
(27.98)\end{array}$ & $\begin{array}{c}52.89^{\mathrm{a}} \\
(26.61)\end{array}$ & 310 & $\begin{array}{c}68.73^{a} \\
(29.72)\end{array}$ & $\begin{array}{l}45.66^{a} \\
(36.29)\end{array}$ & $\begin{array}{l}58.84^{\mathrm{ab}} \\
(25.39)\end{array}$ & 211 & $\begin{array}{c}66.16^{\mathrm{a}} \\
(28.98)\end{array}$ & $\begin{array}{c}44.78^{a} \\
(33.80)\end{array}$ & $\begin{array}{c}60.07^{\mathrm{a}} \\
(22.63)\end{array}$ \\
\hline Midwest & 125 & $\begin{array}{c}67.36^{a} \\
(34.17)\end{array}$ & $\begin{array}{c}55.69^{\mathrm{a}} \\
(33.65)\end{array}$ & $\begin{array}{c}51.85^{\mathrm{a}} \\
(30.02)\end{array}$ & 322 & $\begin{array}{c}69.35^{\mathrm{a}} \\
(30.74)\end{array}$ & $\begin{array}{c}46.03^{\mathrm{a}} \\
(34.24)\end{array}$ & $\begin{array}{l}56.59^{\mathrm{ab}} \\
(26.43)\end{array}$ & 236 & $\begin{array}{l}67.44^{\mathrm{a}} \\
(29.66)\end{array}$ & $\begin{array}{l}46.32^{\mathrm{a}} \\
(34.28)\end{array}$ & $\begin{array}{l}56.99^{\mathrm{a}} \\
(22.11)\end{array}$ \\
\hline South & 195 & $\begin{array}{c}65.62^{a} \\
(35.32)\end{array}$ & $\begin{array}{l}53.44^{\mathrm{a}} \\
(37.41)\end{array}$ & $\begin{array}{l}51.49^{a} \\
(36.06)\end{array}$ & 585 & $\begin{array}{c}67.61^{a} \\
(32.66)\end{array}$ & $\begin{array}{l}48.14^{a} \\
(35.54)\end{array}$ & $\begin{array}{l}56.86^{a} \\
(25.14)\end{array}$ & 401 & $\begin{array}{l}66.23^{a} \\
(28.80)\end{array}$ & $\begin{array}{l}44.09^{a} \\
(33.71)\end{array}$ & $\begin{array}{c}59.53^{a} \\
(24.45)\end{array}$ \\
\hline West & 140 & $\begin{array}{c}68.36^{a} \\
(34.64)\end{array}$ & $\begin{array}{c}56.01^{\mathrm{a}} \\
(34.81)\end{array}$ & $\begin{array}{l}51.54^{\mathrm{a}} \\
(41.52)\end{array}$ & 359 & $\begin{array}{c}71.25^{\mathrm{a}} \\
(29.83)\end{array}$ & $\begin{array}{l}48.13^{a} \\
(36.47)\end{array}$ & $\begin{array}{c}60.20^{\mathrm{b}} \\
(23.74)\end{array}$ & 267 & $\begin{array}{c}67.65^{a} \\
(31.46)\end{array}$ & $\begin{array}{l}44.92^{\mathrm{a}} \\
(34.05)\end{array}$ & $\begin{array}{c}58.75^{\mathrm{a}} \\
(23.90)\end{array}$ \\
\hline
\end{tabular}

\section{B. Republicans}

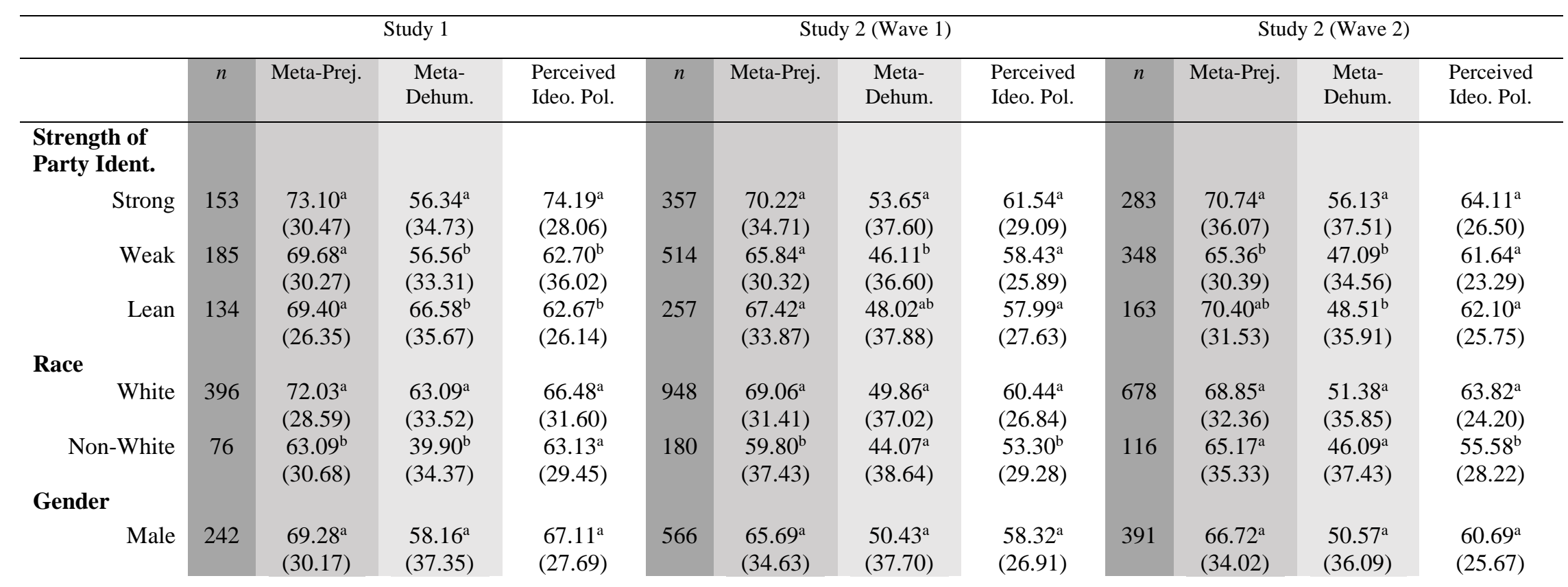




\begin{tabular}{|c|c|c|c|c|c|c|c|c|c|c|c|c|}
\hline Female & 230 & $\begin{array}{c}71.92^{\mathrm{a}} \\
(27.92)\end{array}$ & $\begin{array}{c}60.62^{a} \\
(31.74)\end{array}$ & $\begin{array}{c}64.71^{a} \\
(34.63)\end{array}$ & 562 & $\begin{array}{c}69.49^{a} \\
(30.34)\end{array}$ & $\begin{array}{c}47.43^{a} \\
(36.92)\end{array}$ & $\begin{array}{c}60.30^{\mathrm{a}} \\
(27.77)\end{array}$ & \multirow[t]{2}{*}{403} & $\begin{array}{c}69.87^{a} \\
(31.56)\end{array}$ & $\begin{array}{c}50.64^{a} \\
(36.17)\end{array}$ & $\begin{array}{c}64.48^{b} \\
(24.17)\end{array}$ \\
\hline Age & & & & & & & & & & & & \\
\hline $18-34$ & 124 & $\begin{array}{c}67.82^{\mathrm{a}} \\
(27.03)\end{array}$ & $\begin{array}{c}52.73^{\mathrm{a}} \\
(36.23)\end{array}$ & $\begin{array}{c}56.52^{\mathrm{a}} \\
(38.52)\end{array}$ & 443 & $\begin{array}{c}62.56^{\mathrm{a}} \\
(35.24)\end{array}$ & $\begin{array}{c}47.42^{\mathrm{a}} \\
(37.85)\end{array}$ & $\begin{array}{c}55.66^{\mathrm{a}} \\
(29.73)\end{array}$ & 251 & $\begin{array}{c}62.99^{\mathrm{a}} \\
(37.28)\end{array}$ & $\begin{array}{c}48.52^{\mathrm{a}} \\
(36.78)\end{array}$ & $\begin{array}{c}60.93^{\mathrm{a}} \\
(27.98)\end{array}$ \\
\hline $35-49$ & 115 & $\begin{array}{c}74.78^{\mathrm{a}} \\
(31.63)\end{array}$ & $\begin{array}{l}59.81^{\mathrm{ab}} \\
(34.59)\end{array}$ & $\begin{array}{c}68.32^{\mathrm{b}} \\
(26.25)\end{array}$ & 424 & $\begin{array}{c}69.81^{\mathrm{b}} \\
(30.65)\end{array}$ & $49.05^{\mathrm{a}}$ & $61.70^{\mathrm{b}}$ & 336 & $\begin{array}{l}70.59^{\mathrm{b}} \\
(31.05)\end{array}$ & $52.26^{\mathrm{a}}$ & $\begin{array}{r}64.39^{\mathrm{a}} \\
(2371)\end{array}$ \\
\hline $50-64$ & 142 & $\begin{array}{l}71.77^{\mathrm{a}} \\
(28.75)\end{array}$ & $\begin{array}{c}61.85^{\mathrm{b}} \\
(33.43)\end{array}$ & $\begin{array}{l}71.28^{b} \\
(28.55)\end{array}$ & 205 & $\begin{array}{c}71.46^{\mathrm{b}} \\
(31.48)\end{array}$ & $\begin{array}{l}52.85^{\mathrm{a}} \\
(36.16)\end{array}$ & $\begin{array}{c}62.11^{\mathrm{b}} \\
(26.56)\end{array}$ & 161 & $\begin{array}{l}71.67^{\mathrm{b}} \\
(29.81)\end{array}$ & $\begin{array}{l}52.35^{\mathrm{a}} \\
(37.10)\end{array}$ & $\begin{array}{r}62.52^{\mathrm{a}} \\
(23.75)\end{array}$ \\
\hline $65+$ & 91 & $\begin{array}{c}67.10^{a} \\
(28.65)\end{array}$ & $\begin{array}{c}64.29^{b} \\
(33.66)\end{array}$ & $\begin{array}{c}67.40^{b} \\
(27.58)\end{array}$ & 53 & $\begin{array}{c}75.36^{b} \\
(23.07)\end{array}$ & $\begin{array}{l}46.53^{a} \\
(40.73)\end{array}$ & $\begin{array}{l}59.45^{a b} \\
(24.45)\end{array}$ & 46 & $\begin{array}{l}69.04^{a b} \\
(26.05)\end{array}$ & $\begin{array}{c}43.80^{\mathrm{a}} \\
(32.92)\end{array}$ & $\begin{array}{l}59.21^{\mathrm{a}} \\
(20.03)\end{array}$ \\
\hline $\begin{array}{l}\text { HS or } \\
\text { Below }\end{array}$ & 186 & $\begin{array}{c}70.23^{a} \\
(29.08)\end{array}$ & $\begin{array}{l}57.26^{\mathrm{a}} \\
(34.09)\end{array}$ & $\begin{array}{c}68.86^{\mathrm{a}} \\
(34.43)\end{array}$ & 141 & $\begin{array}{c}66.43^{a} \\
(33.89)\end{array}$ & $\begin{array}{l}47.50^{\mathrm{ab}} \\
(35.01)\end{array}$ & $\begin{array}{l}56.74^{\mathrm{a}} \\
(29.17)\end{array}$ & 94 & $\begin{array}{c}63.66^{a} \\
(35.39)\end{array}$ & $\begin{array}{c}50.68^{a} \\
(38.40)\end{array}$ & $\begin{array}{l}59.02^{\mathrm{a}} \\
(28.66)\end{array}$ \\
\hline $\begin{array}{r}\text { Some } \\
\text { College }\end{array}$ & 123 & $\begin{array}{c}67.99^{a} \\
(32.74)\end{array}$ & $\begin{array}{c}61.27^{\mathrm{a}} \\
(36.14)\end{array}$ & $\begin{array}{c}62.95^{\mathrm{a}} \\
(34.17)\end{array}$ & 378 & $\begin{array}{c}69.85^{a} \\
(31.79)\end{array}$ & $\begin{array}{c}52.58^{a} \\
(38.02)\end{array}$ & $\begin{array}{c}59.71^{\mathrm{a}} \\
(28.45)\end{array}$ & 263 & $\begin{array}{c}68.80^{\mathrm{a}} \\
(33.72)\end{array}$ & $\begin{array}{c}52.71^{\mathrm{a}} \\
(34.21)\end{array}$ & $\begin{array}{l}63.85^{\mathrm{a}} \\
(25.23)\end{array}$ \\
\hline $\mathrm{BA}+$ & 164 & $\begin{array}{c}72.90^{\mathrm{a}} \\
(26.03)\end{array}$ & $\begin{array}{c}60.31^{\mathrm{a}} \\
(34.34)\end{array}$ & $\begin{array}{c}64.85^{\mathrm{a}} \\
(24.35)\end{array}$ & 609 & $\begin{array}{c}66.45^{a} \\
(32.78)\end{array}$ & $\begin{array}{c}47.00^{b} \\
(37.30)\end{array}$ & $\begin{array}{c}59.66^{\mathrm{a}} \\
(26.20)\end{array}$ & 437 & $\begin{array}{c}69.03^{a} \\
(31.66)\end{array}$ & $\begin{array}{c}49.32^{a} \\
(36.73)\end{array}$ & $\begin{array}{l}62.64^{\mathrm{a}} \\
(23.94)\end{array}$ \\
\hline \multicolumn{13}{|l|}{ Region } \\
\hline Northeast & 63 & $\begin{array}{c}69.75^{\mathrm{a}} \\
(31.36)\end{array}$ & $\begin{array}{c}58.29^{\mathrm{a}} \\
(33.99)\end{array}$ & $\begin{array}{c}69.09^{\mathrm{a}} \\
(26.37)\end{array}$ & 171 & $\begin{array}{c}62.08^{\mathrm{a}} \\
(35.27)\end{array}$ & $\begin{array}{c}47.35^{\mathrm{a}} \\
(38.06)\end{array}$ & $\begin{array}{c}55.86^{\mathrm{a}} \\
(29.75)\end{array}$ & 107 & $\begin{array}{c}68.07^{\mathrm{a}} \\
(31.87)\end{array}$ & $\begin{array}{c}49.66^{\mathrm{a}} \\
(36.13)\end{array}$ & $\begin{array}{l}62.15^{\mathrm{a}} \\
(26.32)\end{array}$ \\
\hline Midwest & 111 & $\begin{array}{c}69.25^{\mathrm{a}} \\
(29.06)\end{array}$ & $\begin{array}{c}57.66^{\mathrm{a}} \\
(30.96)\end{array}$ & $\begin{array}{c}69.36^{\mathrm{a}} \\
(25.97)\end{array}$ & 226 & $\begin{array}{l}67.71^{\mathrm{ab}} \\
(31.40)\end{array}$ & $\begin{array}{c}47.49^{\mathrm{a}} \\
(37.10)\end{array}$ & $\begin{array}{c}60.85^{\mathrm{a}} \\
(25.59)\end{array}$ & 171 & $\begin{array}{c}68.73^{a} \\
(31.96)\end{array}$ & $\begin{array}{c}50.21^{\mathrm{a}} \\
(35.60)\end{array}$ & $\begin{array}{l}63.13^{\mathrm{a}} \\
(23.82)\end{array}$ \\
\hline South & 203 & $\begin{array}{c}69.46^{a} \\
(29.60)\end{array}$ & $\begin{array}{c}60.05^{a} \\
(35.75)\end{array}$ & $\begin{array}{c}63.73^{a} \\
(33.61)\end{array}$ & 484 & $\begin{array}{c}68.15^{b} \\
(32.44)\end{array}$ & $\begin{array}{l}48.91^{a} \\
(37.50)\end{array}$ & $\begin{array}{c}59.06^{\mathrm{a}} \\
(27.64)\end{array}$ & 338 & $\begin{array}{c}68.46^{a} \\
(32.64)\end{array}$ & $\begin{array}{c}50.59^{a} \\
(36.35)\end{array}$ & $\begin{array}{l}63.06^{a} \\
(24.91)\end{array}$ \\
\hline West & 96 & $\begin{array}{r}74.88^{a} \\
(26.53)\end{array}$ & $\begin{array}{c}60.64^{\mathrm{a}} \\
(37.29)\end{array}$ & $\begin{array}{c}64.58^{a} \\
(34.42)\end{array}$ & 245 & $\begin{array}{c}70.29^{b} \\
(31.89)\end{array}$ & $\begin{array}{l}51.45^{\mathrm{a}} \\
(36.87)\end{array}$ & $\begin{array}{c}61.19^{a} \\
(26.25)\end{array}$ & 177 & $\begin{array}{c}67.85^{\mathrm{a}} \\
(34.81)\end{array}$ & $\begin{array}{c}51.58^{\mathrm{a}} \\
(36.49)\end{array}$ & $\begin{array}{c}61.82^{\mathrm{a}} \\
(25.37)\end{array}$ \\
\hline
\end{tabular}

Notes. Study 1 means are weighted; Ideological Polarization (perceived ingroup mean vs. perceived outgroup mean) for Study 1 concerns Border Policy and Study 2 is the average of Perceived Border Policy, Perceived Gun Policy, and Perceived Police vs. Civilian Culpability; Race binned to 'White' and 'non-White' since sample sizes for individual non-White Republican racial groups was too small for analysis ( $n s<44)$; Superscript comparisons are within variable and within subgroup; Values that share the same superscript did not differ from each other (t-test $p>.05)$, values with different superscripts differed from each other $(t$-test $p<.05)$. 
Table S5. Study 2 descriptive statistics and variable intercorrelations for samples of Democrats (A) and Republicans (B) assessed at 2 waves.

\section{A. Democrats}

\begin{tabular}{|c|c|c|c|c|c|c|c|c|c|}
\hline & 1 & 2 & 3 & 4 & 5 & 6 & 7 & 8 & 9 \\
\hline 1. Prejudice & $.68 * * *$ & $.54 * * *$ & $.35 * * *$ & $.33 * * *$ & $.25 * * *$ & $.23 * * *$ & $.29 * * *$ & $.37 * * *$ & $.37 * * *$ \\
\hline 2. Dehumanization & $.49 * * *$ & $.59 * * *$ & $.24 * * *$ & $.40 * * *$ & $.19 * * *$ & $.14 * * *$ & $.14 * * *$ & $.37 * * *$ & $.33 * * *$ \\
\hline 3. Meta-Prejudice & $.37 * * *$ & $.21 * * *$ & $.53 * * *$ & $.52 * * *$ & $.33 * * *$ & $.30 * * *$ & $.38 * * *$ & $.12 * * *$ & $.09 * * *$ \\
\hline 4. Meta-Dehumanization & $.27 * * *$ & $.39 * * *$ & $.50 * * *$ & $.57 * * *$ & $.26 * * *$ & $.22 * * *$ & $.27 * * *$ & $.21 * * *$ & $.20 * * *$ \\
\hline 5. Border Policy & $.19 * * *$ & $.14 * * *$ & $.34 * * *$ & $.26 * * *$ & $.51 * * *$ & $.46 * * *$ & $.45 * * *$ & .05 & .02 \\
\hline 6. Gun Policy & $.19 * * *$ & $.13 * * *$ & $.30 * * *$ & $.22 * * *$ & $.43 * * *$ & $.56 * * *$ & $.42 * * *$ & $.06^{*}$ & .02 \\
\hline 7. Police Culpability & $.27 * * *$ & $.16^{* * * *}$ & $.38 * * *$ & $.24 * * *$ & $.47 * * *$ & $.41 * * *$ & $.51 * * *$ & $.08 * *$ & $.05 *$ \\
\hline 8. Social Distancing & $.36 * * *$ & $.34 * * *$ & $.15^{* * * *}$ & $.23 * * *$ & .05 & $.10 * *$ & $.15^{* * *}$ & $.75 * * *$ & $.47 * * *$ \\
\hline 9. Outgroup Spite & $.31 * * *$ & $.36^{* * * *}$ & $.15^{* * * *}$ & $.26 * * *$ & .03 & $.09 * *$ & $.12 * * *$ & $.47 * * *$ & $.78 * * *$ \\
\hline Wave $1 \underline{M} s$ & 42.01 & 18.36 & 69.01 & 47.26 & 59.83 & 59.15 & 54.76 & 39.00 & 3.73 \\
\hline Wave 1 SDs & 34.66 & 30.00 & 31.11 & 35.66 & 28.86 & 33.92 & 32.47 & 30.01 & 1.30 \\
\hline Wave $2 M \mathrm{~s}$ & 40.73 & 18.19 & 66.81 & 44.89 & 59.33 & 60.90 & 56.40 & 38.94 & 3.60 \\
\hline Wave $2 S D$ s & 33.39 & 28.99 & 29.64 & 33.90 & 27.98 & 30.52 & 30.82 & 29.93 & 1.30 \\
\hline
\end{tabular}

\section{B. Republicans}

\begin{tabular}{|c|c|c|c|c|c|c|c|c|c|}
\hline & 1 & 2 & 3 & 4 & 5 & 6 & 7 & 8 & 9 \\
\hline 1. Prejudice & $.69 * * *$ & $.56 * * *$ & $.37 * * *$ & $.37 * * *$ & $.32 * * *$ & $.23 * * *$ & $.25 * * *$ & $.43 * * *$ & $.45 * * *$ \\
\hline 2. Dehumanization & $.61 * * *$ & $.68 * * *$ & $.20 * * *$ & $.38 * * *$ & $.21 * * *$ & $.14 * * *$ & $.10 * *$ & $.41 * * *$ & $.47 * * *$ \\
\hline 3. Meta-Prejudice & $.37 * * *$ & $.25 * * *$ & $.60 * * *$ & $.56 * * *$ & $.48 * * *$ & $.42 * * *$ & $.39 * * *$ & $.12 * * *$ & $.10 * *$ \\
\hline 4. Meta-Dehumanization & $.40 * * *$ & $.42 * * *$ & $.54 * * *$ & $.59 * * *$ & $.34 * * *$ & $.30 * * *$ & $.28 * * *$ & $.23 * * *$ & $.23 * * *$ \\
\hline 5. Border Policy & $.26 * * *$ & $.18 * * *$ & $.43 * * *$ & $.31 * * *$ & $.52 * * *$ & $.52 * * *$ & $.45 * * *$ & $.10 * *$ & $.08 * *$ \\
\hline
\end{tabular}




\begin{tabular}{ccccccccccc} 
6. Gun Policy & $.21 * * *$ & $.12 * *$ & $.33 * * *$ & $.26 * * *$ & $.57 * * *$ & $.61 * * *$ & $.41 * * *$ & $.06 *$ & .03 \\
7. Police Culpability & $.20 * * *$ & .05 & $.36 * * *$ & $.27 * * *$ & $.43 * * *$ & $.42 * * *$ & $.55 * * *$ & $.09 * *$ & .03 \\
8. Social Distancing & $.45 * * *$ & $.47 * * *$ & $.20 * * *$ & $.31 * * *$ & .04 & .06 & .05 & $.75 * * *$ & $.55 * * *$ \\
9. Outgroup Spite & $.49 * * *$ & $.47 * * *$ & $.15 * * *$ & $.29 * * *$ & $.08 *$ & .04 & .01 & $.52 * * *$ & $.78 * * *$ \\
\hline Wave 1 $\underline{M} s$ & 35.98 & 17.73 & 67.59 & 48.93 & 63.77 & 62.54 & 51.37 & 32.00 & 3.35 \\
Wave 1 SDs & 36.07 & 30.78 & 32.60 & 37.33 & 31.44 & 36.09 & 35.56 & 28.85 & 1.35 \\
Wave 2 Ms & 38.21 & 18.42 & 68.32 & 50.61 & 66.22 & 66.26 & 55.37 & 33.48 & 3.39 \\
Wave 2 SDs & 34.85 & 29.90 & 32.81 & 36.11 & 27.67 & 31.42 & 34.03 & 29.40 & 1.41 \\
\hline
\end{tabular}

Notes. Above the diagonal line in italics $=$ Wave 1, below the diagonal line $=$ Wave 2, on the diagonal line in bold $=$ Wave 1 correlation with the same Wave 2 variable; $* p<.05, * * p<0.01, * * * p<.001$. 